\title{
UN MANUSCRITO AUTÓGRAFO DEL PADRE SOLER EN ORIHUELA CON EL FINAL DE DIDONE ABBANDONATA Y OTRAS COMPOSICIONES INÉDITAS
}

\author{
A MANUSCRIPT AUTOGRAPH OF THE FATHER SOLER IN \\ ORIHUELA WITHTHE END OF DIDONE ABBANDONATA AND OTHER \\ HITHERTO UNKNOW COMPOSITIONS
}

\author{
JUAN BERNÁ PÉREZ
}

IES Ramón Otero Pedrayo, A Coruña

Al maestro José Luis López García

\section{RESUMEN}

Las catalogaciones realizadas en 1909 y 1986 del Archivo de Música de la Catedral de Orihuela (ACO), asignaron al Padre Antonio Soler tres títulos sin advertir que el manuscrito con signatura 52/4, después del villancico $A$ velar, pastores de Belén, tenía anotadas otras seis composiciones de la misma mano, fechadas entre 1763 y 1779. Este artículo tiene como objetivos catalogar y describir los siete títulos del manuscrito ACO 52/4, contextualizar su contenido y establecer los factores que permiten identificar al Padre Soler (1729-1783) como su autor $y$ redactor. Se trata de un hallazgo doblemente importante porque incorpora seis títulos al catálogo de uno de los compositores españoles más importantes $\mathrm{y}$, además, ofrece una faceta desconocida de su actividad creativa, pues uno de ellos pone música a la escena final de Didone abbandonata de Pietro Metastasio.

PALABRAS CLAVE: Padre Antonio Soler, Didone abbandonata, Catedral de Orihuela, San Lorenzo de El Escorial, música española del siglo XVIII.

\section{ABSTRACT}

The 1909 and 1986 catalogues

Copyright: (C) 2020 Servicio de Publicaciones de la Universidad de Murcia (Spain). Este es un artículo de acceso abierto distribuido bajo los términos de la licencia Creative Commons Reconocimiento 4.0 Internacional (CC BY 4.0). 
of the Musical Archive in Orihuela Cathedral (ACO) assigned Father Antonio Soler three titles, without noticing that the manuscript 52/4 had, after the villancico $A$ velar, pastores de Belén, another six compositions in his own handwriting, dated between 1763 and 1779. The purpose of this article is to catalogue and describe the seven titles of the manuscript ACO 52/4, to contextualize its contents and to establish the factors that allow us to identify Father Antonio Soler (1729-
1738) as its author. This is a doubly important find as it adds six titles to the catalogue of one of the most important Spanish composers, moreover, it offers an unknown facet of his creative activity, as one of them is the final scene of Pietro Metastasio's Didone abbandonata.

KEYWORDS: Father Antonio Soler, Didone abbandonata, Orihuela Cathedral, San Lorenzo de El Escorial, Spanish music of the 18th century.

\section{INTRODUCCIÓN Y OBJETIVOS DE ESTUDIO: TÍTULOS NO CATALOGADOS DEL MANUSCRITO ACO 52/4}

Carlos Moreno (1874-1962) terminó en 1909 el Inventario del Archivo de Música de la Catedral de Orihuela (ACO) que constituye la catalogación más antigua de estos materiales que ha llegado hasta nosotros y que, además, sigue en uso actualmente. Este manuscrito (Moreno, 1909) se divide en tres índices: el primero incluye obras contenidas en carpetas grandes (pp. 3-80), el segundo obras contenidas en carpetas pequeñas (pp. 81-124) y el tercero «obras contenidas en libros de coro, música profana, obras de Ginés Pérez y varios» (pp. 125-137). El contenido de carpetas grandes y pequeñas sigue un criterio litúrgico que era el habitual cuando estos materiales estuvieron en uso. Posiblemente Carlos Moreno se limitó a hacer inventario, sin alterar su organización, concediendo un número a cada carpeta y anotando el orden de los materiales de cada una, identificados por título, autor, número de voces, si estaba completo o no, si constaba en partitura o partichelas y si incluía orquesta, pero sin especificar la formación de esta. Desde entonces cada título de este archivo musical se ha identificado por una signatura consistente en dos números: el primero indica la carpeta (bien grande o pequeña) y el segundo el número del orden asignado dentro de ella.

José Climent realizó una segunda catalogación publicada en 1986 con el título Fondos musicales de la Región Valenciana. IV Catedral de Orihuela. Climent no alteró ni el orden ni la signatura concedidas por Carlos Moreno con la salvedad de designar como legajos a las carpetas y aunar en una signatura obras que tenían dos o más; también mantuvo la signatura de las incorporaciones posteriores a 1909 todas ellas con la indicación "Carp.» (Climent, 1986: 9-10). Climent divide su publicación en dos partes: Libros de Partitura de Atril (pp. 11-24) y Música en Legajos (pp. 25-254). Los materiales enumerados en la primera parte también figuran en la segunda que, por lo 
tanto, incluye todo el fondo. Esta segunda parte está organizada alfabéticamente por autores, incorporando una reseña biográfica de aquellos que considera más representativos y concediendo un número a cada título. Esta catalogación de Climent, a pesar de su destacada importancia, presenta ciertas limitaciones derivadas de no haber cotejado directamente las fuentes: los títulos carecen de íncipit musical, no se distingue entre título propio y uniforme, se catalogan como obras diferentes partitura y partichelas de una misma composición y se omiten algunas composiciones que comparten los materiales de otra, tal y como ocurre con el manuscrito que nos ocupa.

En el catálogo de Climent (1986) corresponden al Padre Antonio Soler los números 1630, 1631 y $1632^{1}$. El número 1631 identifica el villancico $A$ velar, pastores de Belén al que Carlos Moreno (1909) le había concedido la signatura 52/4 (p. 59). Carlos Moreno y después José Climent, sin reparar en el contenido completo de este manuscrito, catalogaron solo el primer título que atribuyeron al Padre Antonio Soler porque en el folio 1r, se lee este apellido como identificación del autor: "Villan[ci]co Segundo del año 1763. Navidad. Soler» (Cuadro 1).

En 1980, los profesores Antonio Serna Serna, catedrático de Física-Química de la Universidad de Murcia y José Luis López García, catedrático de Dirección del Conservatorio Superior de Música de Murcia, realizaron una microfilmación del archivo de la catedral de Orihuela (Serna y López, 1980). Ambos repararon en el contenido completo del manuscrito 52/4 e incluso el profesor López García transcribió en 1983 los cinco títulos iniciales con intención de ofrecerlos al público (López, 1983). La ocasión llegó el 9 de marzo de 1984 y tuve la fortuna de formar parte del conjunto que los interpretó; esta experiencia inició mi interés por la investigación musical ${ }^{2}$.

Mi relación docente y personal con ambos maestros me permitió conocer estos trabajos que lamentablemente han permanecido sin publicar. Sus investigaciones han

\footnotetext{
${ }^{1}$ Climent, 1986: 246. El número 1630 corresponde a la signatura 27/5 que identifica un manuscrito consistente en un cuadernillo de 10 folios en formato horizontal cosidos en su centro. En la parte superior del fol. 1r se lee como título propio «Missa a 4 y 8 con Violines y Trom[pa]s (Numº. 223) De F[ray]. Ant[oni]o Soler». Es una composición para SSAT/ SATB, dos violines, trompas y acompañamiento cifrado. El coro primero y los instrumentos están copiados en formato de partitura y entre las pautas $5^{\mathrm{a}} \mathrm{y}$ $6^{\mathrm{a}}$ del fol. 1r se anotó: «el $2^{\mathrm{o}}$. Coro está en la Oja $9^{\mathrm{a}}$ a la Plana $2^{\mathrm{a}}$ ». Efectivamente el coro segundo está copiado a partir del fol. 9v en cuyo encabezamiento se lee: «Segundo Coro a la Missa de $6^{\circ}$ Tono de F. Ant $^{\circ}$. Soler.». Es una copia muy cuidada sin fechar que se identifica con una misa cuyas partichelas se conservan en El Escorial con número de catálogo 1620 (Rubio, 1976: 495). Volviendo al catálogo de Climent, el número 1632 corresponde a la signatura 54/26 que identifica un grupo de 11 partichelas cuidadosamente copiadas con una portada en reverso de partichela de violín 1 en la que consta « $\mathrm{N}^{\circ} 310$ / Aria a el SSm\%/ siento ay de mi/ Con Violines Trompas y Baso/ De el Sigr. Soler». Climent le concede el título de Cuanto descubro en ti porque es el inicio del recitado que antecede al aria. Se trata de un recitado y aria al Santísimo Sacramento para alto o para tenor (también hay partichela), violines, trompas y acompañamiento que se inicia y concluye en mi bemol mayor. En el texto de la partichela de alto se escribe «Madre mía», debajo de las palabras «Dios mío» posiblemente para ser utilizada en ceremonias marianas. Los números ordinales que se anotaron en la portada de ambos documentos (27/5 y 54/26) pudieron ser resultado de un inventario.

${ }^{2}$ El concierto tuvo lugar el viernes 9 de marzo de 1984 en el salón de Actos del Conservatorio Superior de Música de Murcia (entonces ubicado en el Teatro Romea), dentro del Ciclo de Extensión Artística Docente, audición $6^{a}$ del curso académico 1983-1984. Intervino el Coro y la Orquesta del Conservatorio de Música de Murcia bajo la dirección del profesor José Luis López García. Se interpretaron cuatro composiciones del Padre Soler del manuscrito ACO 52/4: Auras traviesas, Una zagaleja, Un maestro de capilla y $A$ velar pastores de Belén.
} 
constituido el punto de partida de mi tesis doctoral y de este artículo que tiene como objetivo inventariar el contenido del manuscrito 52/4, establecer los factores que permiten identificar como su redactor al Padre Antonio Soler, uno de los principales compositores españoles, así como contextualizar su contenido.

En el transcurso de la elaboración de este artículo, siendo profesor de oboe y coro en el Conservatorio Profesional de Música de A Coruña, transcribí y se interpretó Un maestro de Capilla el 20 de diciembre de 2016 y el 26 de marzo de 2017 (Pérez, 2017). Estos son los únicos acercamientos a este manuscrito de los que tengo constancia, más allá de su catalogación incompleta realizada por Carlos Moreno y José Climent cuyos trabajos solo hacen referencia a la primera de las siete composiciones anotadas en él.

\section{EL MANUSCRITO ACO 52/4}

\subsection{DESCRIPCIÓN}

El manuscrito ACO 52/4 consta de 8 pliegos (de $432 \mathrm{~mm}$ x $311 \mathrm{~mm}$ aproximadamente) pautados a mano y cosidos en su centro formando un cuadernillo de formato vertical cuya dimensión aproximada cerrado es de $215 \mathrm{~mm}$ x $311 \mathrm{~mm}$. El cuadernillo resultante consta de 16 folios, numerados correlativamente en el frente (recto) desde el folio 2, excepto el que figura entre el 14 y el 15 que no está numerado y ha sido identificado como 14bis. El anverso del primer folio (fol. 1r) tiene 20 pautas; su reverso (fol. 1v) y todos los folios hasta el 14bisr, cuentan con 24 pautas; el folio 15 se rasgó a la altura de la pauta 13 en la que se había anotado música en ambas caras. En todos los folios las pautas se agrupan de cuatro en cuatro y se trazaron en una tinta ligeramente ocre. Las divisorias que se rayaron a cordel en tinta más oscura, atraviesan todo el folio perpendicularmente a las pautas, formando compases espaciados regularmente lo cual indica que se trazaron antes de anotar la música (Imagen 1).

El papel presenta una filigrana que se aprecia con claridad en el fol. 14bis, consistente en corona de príncipe de sangre francés sobre flor de lis de la que cuelgan dos óvalos concéntricos festoneados con círculos (posiblemente toisón). Debajo de todo ello, figuran las letras $\langle\mathrm{G} B » y$ y $\langle\mathrm{F} »$ entre ambas y en un nivel inferior. La heráldica de esta filigrana identifica un papel de posible origen francés, que circuló en España y en Portugal desde el siglo XVII y en buena parte del XVIII ${ }^{3}$.

La notación de cada pentagrama permite completar las escasas indicaciones organológicas (Cuadros 1 al 7) y establecer con seguridad el destinatario de cada uno de ellos. Las partes vocales se anotan en claves bajas y las instrumentales en tesitura real con las correspondientes armaduras, sin precisar transporte para ninguna de ellas. Las dos partes de violines, oboes y flautas se escriben respectivamente en pautas distintas, no así las trompas primera y segunda que figuran en una sola pauta en clave de fa o sol según la tesitura del instrumento, siguiendo un procedimiento habitual en la época

3 Idéntica filigrana aparece reproducida y descrita en estos términos por Soliva, 2016: 23-25. Esta filigrana se ha localizado en documentos vinculados a la hacienda pública, registros notariales y a órganos de gobierno religiosos y civiles correspondientes al periodo transcurrido entre 1627 y 1764. 
(Valls, 1742: fol 144r). El bajo continuo o acompañamiento (fol. 105v-106r), se anota en una sola pauta en clave fa y sin cifrar. La ordenación de las partes en cada sistema varía en cada título según su disposición, término usado en la época equivalente al actual orgánico (Pérez, 2008: 559).

Cada sistema transcurre a lo largo de los folios careados de forma que al último compás del reverso de un folio sigue el primero del anverso contiguo. Para aprovechar el papel se disponen dos o más sistemas en cada folio, aunque sean de movimientos distintos. Así ocurre entre los folios $11 \mathrm{v}$ y $14 \mathrm{v}$, donde se anotó el estribillo de Áureas traviesas en las pautas superiores y el recitativo y aria que siguen en las inferiores ${ }^{4}$.

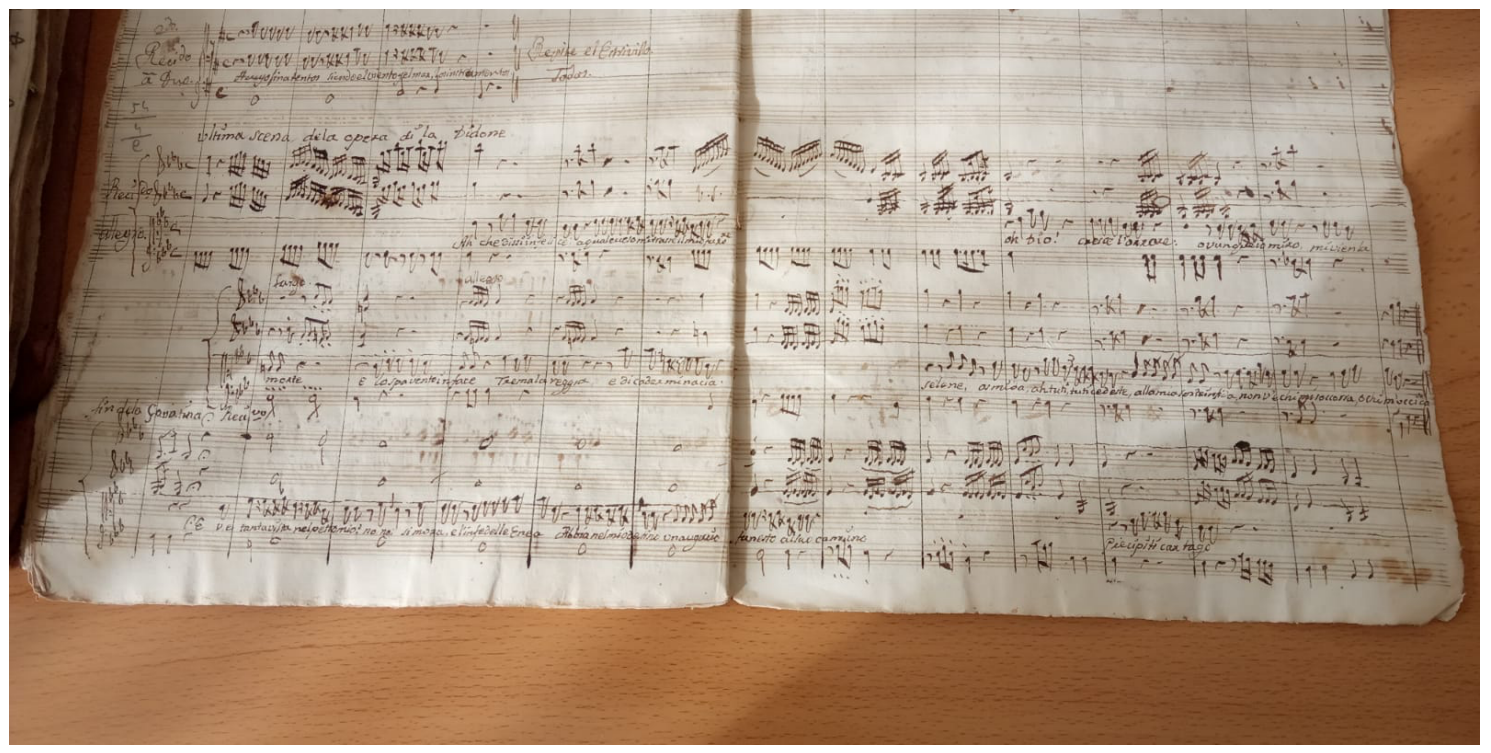

IMAGEN 1. ACO, SIGN. 52/4, FOL. 14V-14BISR

La notación incluye signos de dinámica, agógicos, de articulación, de número de compases en silencio, avisos textuales, guiones para avisar de la nota que sigue en la línea siguiente, calderones para indicar detención del compás o final de la obra y «párrafos para repetir lo mismo que está entre ellos» (Valls, 1742: fol. 22v y 23r), completo o parcialmente si así se indica. En las siete composiciones se usan compases de acentuación gradual que Francisco Valls (1742) llama «modernos» pero también, como era habitual, se mantienen elementos de la tradición mensural en la indicación de compás y en el uso de las divisorias (fol. 225r-229r).

\subsection{IDENTIFICACIÓN Y DESIGNACIÓN DEL CONTENIDO}

El manuscrito ACO 52/4 tiene anotados un total de siete títulos todos ellos con

\footnotetext{
${ }^{4}$ Las pautas 1 a 13 de fol. $11 \mathrm{v}$ al $14 \mathrm{r}$ están ocupadas por el estribillo del villancico Áureas traviesas. El recitativo que le sigue se anota en las pautas 14 a 16 de fol. $11 \mathrm{v}$ y $12 \mathrm{v}$, y su conclusión en pautas 23 y 24 de fol. 11v. El aria ocupa las pautas 17 a 22 de fol. $11 \mathrm{v}$ y 12 r, 15 y 20 de fol. 12v y 13 r, 17 a 22 de fol. $13 \mathrm{v}$ y $14 \mathrm{r}$, y 1 a 6 de fol. $14 \mathrm{v}$ y 14 bisr.
} 
un encabezamiento textual o título propio que contiene información sobre la finalidad de cada uno de ellos. Todos se anotan con una grafía semejante y presentan tachaduras, enmiendas y manchas ${ }^{5}$, evidenciando que se trata de un borrador o primera redacción de estas composiciones. El borrador se realizaba en formato de partitura que, por extensión, también podría denominarse del mismo modo.

El uso y significado del término borrador se ha establecido a partir de manuscritos musicales del archivo de la catedral de Orihuela que lo incluyen en su título propio. Así ocurre en composiciones de Mathías Navarro ${ }^{6}$, Joaquín López ${ }^{7}$, Francisco Grana $^{8}$, Antonio Molina ${ }^{9}$ y Joseph Falguera y Montserrate ${ }^{10}$, organista de la capilla de El Escorial donde profesó en $1795^{11}$.

${ }^{5}$ En los Cuadros 1 al 7 aparecen pormenorizadamente las manchas, tachaduras y enmiendas de cada folio. Las anotaciones a lápiz en los folios $1 \mathrm{r}, 4 \mathrm{r}, 6 \mathrm{v}, 7 \mathrm{v}, 11 \mathrm{v}, 14 \mathrm{v}$, son de fecha reciente pues no estaban hace 20 años y, por ello, no se han tenido en cuenta.

${ }^{6}$ El término borrador está documentado en el título propio de las entradas números1204 y 1254 correspondientes a Mathías Navarro (Climent, 1986: 186, 194). En la portada de la entrada 1204 consta «Borrador de la Misa a 19. / De Matias Navarro. / Año 1689.». A juzgar por la fecha, esta obra fue compuesta durante su magisterio en Elche desarrollado entre 1686 y mayo de 1692 (Pérez, 2008: 177); su grafía es la misma que otros manuscritos autógrafos, pero apenas tiene enmiendas ni tachaduras. En la portada del número 1254 consta «Vísperas a 8 con violines» y de otra mano y tinta «Falta el borrador/ Del Magnificat.». Esta anotación debe referirse a otros materiales pues este manuscrito incluye solo partichelas no autógrafas, posiblemente copiadas en fecha posterior al fallecimiento de Mathías Navarro (Pérez, 2008: 195-229).

${ }^{7} \mathrm{El}$ término borrador está documentado en el título propio de la entrada 921 correspondiente a Joaquín López (Climent, 1986: 148). En su portada que carece de fecha, consta «Borrador de la Missa A 4 y A 8 /Con Violines Trompas y Baxo/ de/ Dn. Joaquín Lopez Presbitero». Este manuscrito tiene enmiendas y tachaduras como corresponde a una primera redacción de la obra. Joaquín López ejerció el magisterio en Segorbe entre 1781 y 1785 , y en Orihuela desde esa fecha hasta su fallecimiento en marzo de 1813 (Pérez, 2013: 150-154).

${ }^{8}$ El término borrador está documentado en el título propio de la entrada 867 correspondiente a Francisco Grana (Climent, 1986: 141). En su portada consta «Borrador/ Al Villancico de Pastorela, con órgano obligado/ Al Nacimiento de N. Sr./ de Mn. Franc ${ }^{\circ}$. Grana/ año 1783»; debajo de todo ello otra mano escribió «Este se ha de cantar». De este compositor se conserva en el archivo de la catedral de Orihuela otra composición datada en 1782. Sobre este compositor poco más se sabe (Climent, 1999-2002a: vol. 5, 826).

${ }^{9}$ El término borrador está documentado en el título propio de las entradas 1083 y 1086 correspondientes a Antonio Molina (Climent, 1986:170). En la portada del número 1083 consta «Borrador al /Villancico a 8 y a 4 con/Violines Obueses y Trompas ad/ libitum de Mn. Antonio/ Molina»; en el encabezamiento de la primera página del borrador consta la fecha de 1784. En la portada del número 1086 consta «Borrador de/ la tonadilla a 4 y a 8 de Dn./ Antonio Molina $\mathrm{p}^{\mathrm{a}}$ el presente/ de 1782». Antonio Molina fue maestro de capilla de la colegiata de Gandía (Climent, 1999-2002a: vol.7, 641).

${ }^{10}$ Según Climent (1986) en el archivo de la catedral de Orihuela hay 40 títulos de este autor (pp. 124130). El título propio de las entradas $755,757,766,767,768,769,777,783,786,787,790$ correspondientes a fray Joseph Falguera y Monserrate (tal y como se identifica en estos manuscritos), se inician con las palabras «Borrador de». Todos estos manuscritos tienen portada y presentan idéntica grafía. El título propio de la portada incluye título de la obra, orgánico, vestuario de los intérpretes en caso de villancicos, fecha y firma del autor; también en la portada figura de otra mano y tinta un número ordinal posiblemente resultado de un inventario (nota 1). Las entradas citadas abarcan el arco temporal comprendido entre 1797 y 1808 y tres de ellas presentan relación con el ceremonial de El Escorial. Estas tres entradas son: la entrada número 777 escrita en 1798 que contiene el himno a san Lorenzo Deus tuorum militum; la entrada 755 una misa dedicada a la Cruz de Caravaca y escrita en 1797 sobre el inicio del mencionado himno; la entrada 790, recitativo y aria datada en 1802, dedicada a San Jerónimo.

${ }^{11}$ Cavia (1999-2002), vol. 4, 894. Joseph Falguera nació en Tarrasa (Barcelona) en 1778 y fue niño de coro en Monserrat entre 1789 y 1794. Ese año entró en la orden jerónima y tomó los votos en el Escorial 
También se anotó este término en el título propio de manuscritos de El Escorial. Tal es el caso del propio Padre Soler quien, para manifestar su destreza compositiva, lo escribió en la parte de continuo de su Salve a 4 y acompañamiento (Rubio 1976: p. 468, n. 1509), considerada autógrafa, donde anotó: «Comp[ues]ta. y escrita por el P[adr]e. Solér en estos mismos papeles [partichelas] sin otro Borrador, en el año de 1779» (p. 661).

Los papeles o partichelas que utilizaban los músicos durante su interpretación se realizaban a partir del borrador que, normalmente, se devolvía al compositor ${ }^{12}$, por este motivo en los archivos eclesiásticos constan más composiciones en partichela. En caso de que se copiara para guardarlo en el archivo, el primer borrador se calificaba como original y el resto copia ${ }^{13}$. Durante la interpretación el maestro marcaba de memoria o utilizaba una copia del papel de acompañamiento, que llamaban guion ${ }^{14}$, palabra que se ha conservado en el argot musical para designar la reducción que hasta fecha reciente se utilizaba para dirigir. El término guion también designaba el documento que recogía los íncipit musicales de las secciones de una composición, posiblemente como procedimiento de archivo $^{15}$. Era habitual que sólo se depositaran en el archivo de los templos las partichelas y partituras realizadas por los copistas de la capilla y aquellos materiales que el órgano de gobierno considerara oportuno, bien por incorporarlas al ceremonial, bien por otros motivos tales como donaciones y adquisiciones en vida o tras el fallecimiento de los maestros ${ }^{16}$. También está documentado en manuscritos musicales

el 22 de noviembre de 1795. Posteriormente fue organista en los Jerónimos de Murcia (Monasterio de La Ñora). Falleció en 1824 posiblemente en Belmonte (Cuenca). Además de los 40 títulos citados del archivo de Orihuela, se conservan obras suyas en El Escorial, el Palacio Real de Madrid y el Monasterio de Guadalupe (Cáceres).

12 Sirva como ejemplo de esta costumbre la anotación hallada en un manuscrito del propio Joseph Falguera y Monserrate que vincula un borrador conservado en Orihuela con las partichelas de la misma obra conservadas en El Escorial. El número 776 (Climent, 1986), que identifica un Veni Creator a 6 con órgano obligado que Joseph Falguera firmó en 1795, el mismo año que profesó, tiene en su portada escrito de otra mano: «este se ha de bolver». En el archivo de El Escorial con la entrada 1207 (Rubio, 1976: 394) se conservan las partichelas elaboradas a partir de este borrador que, efectivamente, le fue devuelto pues a fecha actual está en Orihuela y no en El Escorial. Falguera realizó esta composición para su propia ordenación (p. 394).

${ }^{13}$ El número 763 (Climent, 1986: 126) del archivo catedralicio oriolano se corresponde con un borrador de Joseph Falguera y Monserrate que carece de portada. El título propio se ubica en la primera página y dice lo siguiente «Letanía de Ntra Señora a 4/ con violines, trompas y Acom/ pañamiento; Compuesta $\mathrm{p}^{\mathrm{a}}$ el Capi/ tulo Gral. que ha de celebrar la Orden/ de N. P. San Geronimo, en Sn. Barto/ lomé de Lupiana en el pre. año, por/ M f. José y Monserrate/ Escorial 23 de Marzo/ 1819. Original. № 29».

${ }^{14}$ Sirva como ejemplo una de las partichelas de otra obra del citado Joseph Falguera y Monserrate tal y como consta en Rubio, 1976: 395, n. 1208.

${ }^{15}$ Dos títulos del Padre Soler (Rubio, 1976: 467, 490) conservados en el archivo escurialense contienen una partichela de estas características: el número 1507, tiene guion copiado por el fraile jerónimo Jaime Ferrer (1762-1824) y el número 1602 tiene guion copiado probablemente por el fraile jerónimo Pablo Ramoneda (1743-1792). Recuperado de https://rbmecat.patrimonionacional.es/cgi-bin/koha/opacdetail.pl?biblionumber=40091 y $\quad$ https://rbmecat.patrimonionacional.es/cgi-bin/koha/opacdetail.pl?biblionumber $=40251$ [Consulta 24-6-2020].

${ }^{16}$ Cuando en 1691 el maestro Roque Monserrat dejó el magisterio de la catedral de Orihuela para ocupar el mismo cargo en Murcia, donó al cabildo oriolano una serie de materiales de su autoría (Pérez, 2008: 164). Al año siguiente, cuando Mathías Navarro dejó el magisterio ilicitano para ocupar el mismo puesto en Orihuela, cedió al Consell de Elche un lote de composiciones suyas (pp. 176-177). En 1715 Mathías Navarro dedicó al cabildo unas composiciones suyas que se interpretaban anualmente y que los señores capitulares decidieron encuadernar (pp. 191-192). Cuando Mathías Navarro falleció en 1727 el cabildo oriolano pagó 100 libras por el archivo musical del difunto maestro, cantidad considerable en su contexto 
del archivo catedralicio oriolano, el uso de los términos hoja y plana en lugar de los actuales folio y página respectivamente ${ }^{17}$.

\subsection{RELACIÓN DE TÍTULOS ANOTADOS EN MANUSCRITO ACO 52/4}

En el manuscrito ACO 52/4 constan siete composiciones (Cuadros 1 al 7) identificadas por un título uniforme (en cursiva), procedente del íncipit textual, y un código cifrado, consistente en la signatura del manuscrito seguida de un número que indica el orden en que están anotadas. En la relación que sigue consta además el título propio (entre comillas) y el orgánico en el orden que se anotó en el manuscrito. Estos siete títulos son:

52/4.1, fol. 1r-4r, A velar, pastores de Belén (Cuadro 1)

«Villan[ci]co Segundo del año 1763. Navidad. Soler»

Org.: violín 1 y 2 , oboe 1 y 2, SATB (coro 1), SATB (coro 2), trompas 1 y 2, bajo sin cifrar (acompañamiento).

52/4.2, fol. 4r-6r, Una zagaleja (Cuadro 2)

«Villan[ci]co $7^{\circ}$ de Pastorella par[a] Navidad año 1763»

Orgánico: violín 1 y 2, oboe 1 y 2, SATB, bajo sin cifrar (acompañamiento).

52/4.3, fol. 6v-8r, Entre al Portal la regia Troya bella (Cuadro 3)

«Villan[ci]co $5^{\circ}$ Cantada â solo con violines y flaut[a]s Navidad de [17]63»

Orgánico: violín 1 y 2, flauta 1 y 2, soprano solista, bajo sin cifrar (acompañamiento).

52/4.4, fol. 7v-11r, Un maestro de capilla (Cuadro 4)

«Villan[ci]co 9. de Navidad»

Org.: «poeta»/ A, «maestro»/ B (coro 1), SATB (coro 2), violín 1 y 2, «chirimía» (oboe), bajo sin cifrar (acompañamiento).

52/4.5, fol. 11v-14bisr, Auras traviesas (Cuadro 5).

«Villan[ci]co Primero de reyes de 1764.»

Orgánico: violín 1 y 2, oboe 1 y 2, SATB (coro 1), SATB (coro 2), bajo sin

que recibieron sus hermanos Luis y Anna Navarro como herederos universales (pp. II-VI). En 1813 la hermana del maestro Joaquín López, fallecido el 4 de marzo de 1813, ofreció al cabildo el archivo musical del difunto; el cabildo inventarió estos materiales y los incorporó al archivo de la catedral sin que conste gratificación económica (Pérez, 2013: 154). Los números ordinales anotados en las portadas de los manuscritos de Falguera que conserva el archivo de la sede oriolana, pudieron ser igualmente resultado de un inventario tras su fallecimiento en 1824 (Nota 10).

${ }^{17}$ Así ocurre en una obra de Soler catalogada en Orihuela con signatura 27/5 (Nota 1). 
cifrar(acompañamiento).

52/4.6, fol. 14v-14bisr, Ah che dissi infelice! (Cuadro 6)

«Ultima scena, de la opera di la Didone.»

Orgánico: violín 1 y 2, soprano solista, bajo sin cifrar (acompañamiento).

52/4.7, fol. 14bisr-15v, Mas ay que al eco (Cuadro 7).

«Cantada al Sacra[men]to año de 1779.»

Orgánico: violín 1 y 2, tenor solista, bajo sin cifrar (acompañamiento).

\section{AUTORÍA DEL MANUSCRITO ACO 52/4}

La notación, abreviaturas, indicaciones literarias de repetición, desorden, arrepentimientos, manchas, tachaduras y ausencias fragmentarias de texto que presenta este manuscrito indican que efectivamente se trata del borrador de estas composiciones, es decir, el documento musical en el que un compositor plasmó por escrito su proceso creativo. La identificación de este documento como borrador y la propia firma de su autor que se identifica a sí mismo como «Soler» (Cuadro 1), podría ser motivo suficiente para establecer la identidad del mismo pero, como el manuscrito ACO 52/4 se ha encontrado descontextualizado, se impone un análisis de los factores que permitan vincularlo con la actividad del Padre Antonio Soler como maestro de capilla de San Lorenzo el Real de El Escorial y, además, identificarlo como redactor y autor de su contenido.

Antonio Soler es uno de los compositores españoles más importantes. Nació en Olot (Gerona) donde fue bautizado el 3 de diciembre de 1729. En 1736 ingresó como niño de coro en el Monasterio de Monserrat donde permaneció hasta 1746 y recibió su formación musical. Después de ocupar brevemente el magisterio de Lérida, tomó el hábito jerónimo en El Escorial el 25 de septiembre de 1752 para ocupar el puesto de organista, profesando el 28 de septiembre del año siguiente. En 1754 fue enviado a Madrid para estudiar con José de Nebra y Domenico Scarlatti. A partir de 1755 realizó labores de maestro de capilla, cargo para el que fue designado en 1757 y que desempeñó hasta su fallecimiento el 20 de diciembre de 1783 (Capdepón, 1993: 47-51). Destacan sus composiciones para teclado que siguen la estela de la obra de Domenico Scarlatti.

\subsection{SIMILITUDES DE GRAFÍA CON DOCUMENTOS AUTÓGRAFOS DE ANTONIO SOLER EN EL ESCORIAL}

Samuel Rubio (1980) consideraba la memoria sepulcral de fray Pedro Serra como el único documento autógrafo del Padre Soler pues afirmaba que no se conservaba ningún manuscrito musical de su puño y letra (pp. 39-40, 139). A pesar de esta afirmación el propio Samuel Rubio (1976) había reproducido como autógrafas las portadas de Salve a 4 y acompañamiento y de Seis conciertos de órgano, ambas 
conservadas en El Escorial (pp. 661 y 663). Unos años después Paulino Capdepón (1993) mantenía esta misma opinión, pero advertía que varios manuscritos musicales de obras de Soler presentaban una grafía común que no estaba identificada (p. 56). Catalogaciones recientes han permitido superar esta opinión tan restrictiva, al calificar como autógrafos un buen número de manuscritos de obras de Soler depositados en El Escorial. Del mismo modo José Sierra $(2004 \mathrm{c})$ reproduce como autógrafas varias fuentes musicales y otros documentos (pp.185, 187-188).

El manuscrito ACO 52/4 presenta una grafía textual y musical semejante a la que ofrecen documentos y manuscritos musicales que hoy se consideran autógrafos de Soler, de lo que se deduce que se deben a la misma mano. Concretamente los rasgos descritos para el manuscrito de Orihuela se hallan en las partichelas de la mencionada Salve a 4 y acompañamiento (Rubio, 1976: 468, 661) y en otros cinco manuscritos ${ }^{18}$ del archivo musical de El Escorial en formato borrador, considerados autógrafos y con firma de Soler, cuyos títulos uniformes son Crudelis Herodes. R. $230^{19}$, Viendo tanta Sabandija ${ }^{20}$, Como no es nuevo esta noche ${ }^{21}$, Stabat Mater ${ }^{22}$ y Letanías de la Virgen, voces (8), acompañamiento, do menor ${ }^{23}$.

\subsection{MANUSCRITOS MUSICALES EN EL ESCORIAL CON EL MISMO PAPEL}

Un papel con idéntica filigrana a la descrita en ACO 52/4, se usó en manuscritos musicales de El Escorial. Concretamente se ha localizado en las partichelas del villancico El granero de Belén ${ }^{24}$ de José del Valle fechadas en 1743 y también de las lamentaciones Aleph. Ego vir videns, voces $(8)^{25}$ y Delamentatione... Heth Misericordiae Domini, voces $(8)^{26}$, ambas del propio Padre Soler realizadas antes de 1756.

Esta filigrana constituye un vínculo físico entre el manuscrito 52/4 de Orihuela y

\footnotetext{
${ }^{18}$ Estos cinco manuscritos que se citan a continuación constan en Rubio, 1976: p. 81, [Lp] tomo 20, n. 4, fol. 30r-34v, (Crudelis Herodes) Himno a 4 y ripieno, con violines y trompas ripienas a los Santos Reyes de 1778; p. 81, [Lp] tomo 20, n.7, fol. 43r-48v, Un sacristán y un monaguillo [Viendo tanta sabandija], villancico a 6 de Navidad de 1778; p. 81, [Lp] tomo 20, n.8, fol. 49r-55v, Un Maestro de capilla [Como no es nuevo esta noche], villancico de Navidad de 1774; p. 83, [Lp] tomo 20, n.13a, fol. 95r-98v, Stabat Mater a dúo de 1775; p. 92, [Lp] tomo 23, n.9, fol. 94r-105v, Letanía a Nuestra Señora, a 4 y a 8 con violines de 1765 (en el catálogo pone erróneamente de 1756).

${ }^{19}$ Recuperado de https://rbmecat.patrimonionacional.es/cgi-bin/koha/opac-detail.pl?biblionumber $=37541$ [Consulta 23-6-2020].

${ }^{20}$ Recuperado de https://rbmecat.patrimonionacional.es/cgi-bin/koha/opac-detail.pl?biblionumber=37544 [Consulta 23-6-2020].

${ }^{21}$ Recuperado de https://rbmecat.patrimonionacional.es/cgi-bin/koha/opac-detail.pl?biblionumber $=37545$ [Consulta 23-6-2020].

${ }^{22}$ Recuperado de https://rbmecat.patrimonionacional.es/cgi-bin/koha/opac-detail.pl?biblionumber=37559 [Consulta 23-6-2020].

${ }^{23}$ Recuperado de https://rbmecat.patrimonionacional.es/cgi-bin/koha/opac-detail.pl?biblionumber $=37643$ [Consulta 23-6-2020].

${ }^{24}$ Recuperado de https://rbmecat.patrimonionacional.es/cgi-bin/koha/opac-detail.pl?biblionumber $=40808$ [Consulta 23-6-2020].

${ }^{25}$ Recuperado de https://rbmecat.patrimonionacional.es/cgi-bin/koha/opac-detail.pl?biblionumber=40163 [Consulta 23-6-2020].

${ }^{26}$ Recuperado de https://rbmecat.patrimonionacional.es/cgi-bin/koha/opac-detail.pl?biblionumber=40162 [Consulta 23-6-2020].
} 
la actividad musical de la capilla de El Escorial durante las décadas centrales del siglo XVIII. Allí Soler pudo tener acceso a este papel que utilizó en 1763 para elaborar un cuadernillo de 16 folios que usó inicialmente para anotar cinco composiciones en romance, cuatro para maitines de Navidad de 1763 y otro para epifanía de 1764. Para esta labor utilizó hasta la pauta 11 del folio 14v y la 6 del 14bisr que quedó sin numerar. Una vez las obras se copiaron en papeles para su interpretación, Soler conservó el cuaderno que utilizó posteriormente para anotar los borradores de otros dos títulos. El primero sin fecha y con texto italiano que pone música al episodio de la muerte de Dido, fue anotado a partir de la pauta 13 de los folios 14v y 14bisr (Imagen 1) y en las primeras cuatro del 14bisv. En el espacio restante y de forma un tanto desordenada, escribió en 1779 una cantada al Santísimo Sacramento completando el cuaderno quince años después de su primera entrada y del que se rasgó el último folio a la altura de la pauta 13.

\subsection{RELACIÓN CON EL CEREMONIAL ESCURIALENSE DE NAVIDAD}

En El Escorial, el día 24 de diciembre se interpretaban diez composiciones en romance: la primera a prima después de la calenda y las otras nueve en los maitines solemnes celebrados antes de la misa de gallo, una después de cada responsorio (Rubio1979: 88-91). Según José Sierra era costumbre que el villancico de calenda se repitiera después del primer responsorio de maitines (Sierra 2001: 146), en cuyo caso el maestro sólo precisaba componer nueve.

El manuscrito 52/4 de Orihuela contiene cuatro composiciones en romance destinadas a los maitines de Navidad de 1763. En el archivo de El Escorial no se conservan copias de ninguna de estas cuatro pero sí de otras cinco destinadas a maitines de Navidad de 1763 y catalogadas actualmente con los títulos de Bras aquel pastor antiguo $^{27}$, Una alegre contradanza ${ }^{28}$, Escuchen dos sacristanes ${ }^{29}$, Albricias presos del mundo $^{30}$ y Oyes Gililla aguarda ${ }^{31}$. Estas cinco en cuya cronología también coinciden las catalogaciones precedentes de Samuel Rubio ${ }^{32}$ y Paulino Capdepón ${ }^{33}$, suman nueve junto con las cuatro del manuscrito ACO 52/4; no se ha hallado villancico de calenda para ese año.

Los materiales de los cinco títulos de El escorial se conservan en partichela y

\footnotetext{
${ }^{27}$ Recuperado de https://rbmecat.patrimonionacional.es/cgi-bin/koha/opac-detail.pl?biblionumber=40417 [Consulta 23-6-2020].

${ }_{28}$ Recuperado de https://rbmecat.patrimonionacional.es/cgi-bin/koha/opac-detail.pl?biblionumber $=40428$ [Consulta 23-6-2020].

${ }^{29}$ Recuperado de https://rbmecat.patrimonionacional.es/cgi-bin/koha/opac-detail.pl?biblionumber=40443 [Consulta 23-6-2020].

${ }^{30}$ Recuperado de https://rbmecat.patrimonionacional.es/cgi-bin/koha/opac-detail.pl?biblionumber=40499 [Consulta 23-6-2020].

${ }^{31}$ Recuperado de https://rbmecat.patrimonionacional.es/cgi-bin/koha/opac-detail.pl?biblionumber=40459 [Consulta 23-6-2020].

32 Rubio, 1980: 68. Estos cinco títulos son los correspondientes a los números 105, 106, 107, 109 y 110. Rubio fecha también en 1763 el villancico Gila y Antón con número 108, cuya composición tanto Paulino Capdepón como la Biblioteca del Escorial sitúa en 1762.

${ }^{33}$ Capdepón, 1993: 254. En la información correspondiente al villancico A Belén a ver de 1753 (p. 248 , n.4) se indica que fue interpretado como primero del tercer nocturno en 1763 pero no indica la fuente, dato que no figura en el catálogo actual de la Biblioteca de El Escorial.
} 
presentan indicaciones, en algunos casos más de una, que hacen referencia al responsorio que les precedía, pero no al orden que les correspondía. Paulino Capdepón (1993) advierte que estas indicaciones no fueron frecuentes hasta 1767 y que en muchos casos fueron añadidas con motivo de reposiciones (p. 57). Por el contrario, son autógrafas en las cuatro composiciones de Orihuela, tanto la fecha como la referencia a su orden que consiste en la incorporación al título propio de los ordinales «Segundo», $\left\langle 5^{\circ} »,\left\langle 7^{\circ} » \mathrm{y}\left\langle 9^{\circ}{ }^{\circ}\right] »\right.\right.$ (cuadros $1,2,3$ y 4 ). Estos números pueden referirse bien a los nocturnos que les precedían o al orden total de estas composiciones que, contando el villancico de calenda, serían diez; no obstante, si la calenda se repitió tras el primer responsorio coincidiría el orden con el número de responsorios. El asunto de los textos indica la segunda posibilidad como más plausible pero, de una forma u otra, el orden propuesto en Orihuela se complementa con la información de tres títulos de El Escorial.

Por lo tanto, las cuatro composiciones para Navidad de 1763 del manuscrito ACO 54/2, pudieron ser interpretadas aquel año en El Escorial junto con otras cinco allí conservadas e, incluso se puede establecer el orden de siete de ellas (cuatro del manuscrito de Orihuela y tres de El Escorial). Intriga que en El Escorial no se conserve ninguna copia de los cuatro títulos para maitines de Navidad del manuscrito ACO 52/4; es posible que alguno de ellos fuera descartado pero no lo es tanto que lo fueran todos.

\section{COMPOSICIONES EN CASTELLANO DEL MANUSCRITO ACO 52/4}

Las seis composiciones en castellano anotadas en el manuscrito ACO 52/4 tienen un contexto ceremonial claro y están datadas. Las cuatro primeras dedicadas a maitines de Navidad, responden a un mismo impulso creativo y debieron ser compuestas en otoño de $1763^{34}$. La quinta dedicada a la epifanía de ese mismo ciclo litúrgico, pudo ser escrita en ese mismo periodo o durante la última semana de ese mismo año ${ }^{35}$. Quince años después, en 1779, se anotó el borrador de la cantada al santísimo Sacramento Mas ay que al eco.

\subsection{ORGÁNICO E INTÉRPRETES}

Francesc Valls (1742), informa que las composiciones a 4 con acompañamiento eran habitualmente interpretadas por solistas puesto que el coro de capilla sólo intervenía en las composiciones a 5, a 6 y a 8 identificado como coro 2 (fol. 109v$110 \mathrm{v})$. Esta costumbre explica que en Una zagaleja no se indique «solo» en el inicio del tenor como sí ocurre en el pasaje vocal inicial de $A$ velar, pastores de Belén escrito en el coro 2. El coro de capilla intervendría en $A$ velar, pastores de Belén, Un maestro de capilla y Auras traviesas. Quizás también en la repetición de la tonadilla de Una zagaleja en base a la indicación «Repiten todos la/ Pastorela.» (Cuadro 2), pero ese «todos» también puede indicar los cuatro solistas.

\footnotetext{
${ }^{34}$ Kastner, 1957: 238-239. Una carta de Soler de 30 de noviembre de 1766, revela que en las semanas previas había estado ocupado en la composición de los villancicos de Navidad. Ver nota 50.

${ }^{35}$ Rubio, 1976: 81, [Lp] tomo 20, n.4, fol. 30r-34v. Soler anota en la portada del borrador del Himno Crudelis Herodes. $R 230$ que fue terminado el 31 de diciembre de 1778. Esta portada está reproducida en Sierra, 2004c: 188.
} 
No pocos villancicos de Soler conservados en el Escorial incluyen varias partichelas iguales de violines revelando su interpretación por más de un intérprete por parte (Capdepón, 1993: 56, 240), emulando con las limitaciones de la capilla, el sonido orquestal. La parte de acompañamiento corría a cargo de violonchelo, órgano y/o clave según el elenco vocal (Sierra, 1993: 30). De esta forma el grupo instrumental de $A$ velar, pastores de Belén coincide con la plantilla de la orquesta de cámara clásica (cuerda, dos oboes y dos trompas), con la excepción de la habitual ausencia de violas característica de la música española del siglo XVIII. Al conjunto integrado por violines y acompañamiento, se añaden dos oboes en Una zagaleja y Auras traviesas, dos flautas traveseras en Entre al Portal la regia Troya bella y una parte concertante para «chirimía», posiblemente oboe, en Un maestro de capilla.

\subsection{A VELAR, PASTORES DE BELÉN, VILLANCICO PARA NAVIDAD DE 1763}

Es una composición identificada como «Villan[ci]co segundo del año 1763» (Cuadro 1), para ser interpretada después del segundo responsorio del primer nocturno, cuyo asunto glosa: los pastores que velan en la noche (Lc. 2, 8-20) son sorprendidos por una luz tan intensa como el sol, metáfora de la redención. Se trata de una composición de gran aparato y tono serio cuyo orgánico es también el habitual de los villancicos de calenda de Soler (Capdepón, 1993: 226, 234).

Soler elabora un estribillo en «estilo madrigalesco» (Valls, 1742: fol 174r) mediante la adición de elementos a la tradicional estructura de tonada y responsión (Rubio, 1979: 66, 100-103). Las coplas presentan una estructura estrófica cuya música se repite con tres letras distintas; a todo ello sigue la repetición del «Coro A velar» que constituye la responsión (Cuadro 1).

\subsection{UNA ZAGALEJA, «VILLANCICO DE PASTORELLA» PARA NAVIDAD DE 1763}

Este villancico para cuatro solistas vocales, repite el orgánico instrumental del anterior pero sin trompas y consta de introducción en «estilo madrigalesco» (Valls, 1742: fol. 174r) y «pastorela» a modo de tonadilla (Cuadro 2). Esta composición fue escrita para ser interpretada después del séptimo responsorio (primero del tercer nocturno) de los maitines de Navidad de 1763, cuyo contenido glosa.

El texto del versículo «Venite, gentes et adorate Dominum» constituye una excusa para presentar personajes diversos que llegan al Portal y cantan al Niño. En este caso intervienen arquetipos rústicos identificados por el genérico de pastora y por el nombre propio de Bato (Capdepón, 1993: 109-110). En la introducción se presentan los personajes: una zagala, pastorela o pastorcilla, llega al Portal de Belén y, como tiene gracia y trae sonajas, le piden que cante con Bato al Niño. El texto de la «pastorela» que interpretan a dúo y repiten todos, según la estructura de tonadilla, advierte cómo el llanto del Niño preconiza la Pasión en alusión también al versículo del responsorio «Qui hodie pro salute mundi de Virgine nasci dignatus est».

La «pastorela» se desarrolla en compás binario compuesto sobre esquema rítmico de siciliana. Precisamente este ritmo caracteriza las tonadillas calificadas con el 
término italiano «pastorella» o en su voz castellanizada pastorela.

\subsection{ENTRE AL PORTAL LA REGIA TROYA BELLA, CANTADA PARA NAVIDAD DE 1763}

En el título propio el término villancico es usado en su acepción genérica, con el significado de composición ceremonial en romance (Pérez, 2008: 506). Esta cantada para soprano solista, dos partes de violines, acompañamiento sin cifrar y dos partes de flautas, fue compuesta para ser interpretada después del responsorio quinto (segundo del segundo nocturno) de los maitines de Navidad de 1763 (Cuadro 3).

Esta composición consta de recitativo y aria da capo, lo cual coincide con la descripción y ejemplo de cantada que ofrece Francisco Valls (1742: fol. 196r) y que responde al modelo italiano de cantata breve (Carreras, 2000: 131). La primera sección del aria (A) se desarrolla según el esquema de aria binaria: dos solos que se enmarcan con tres ritornelli, el primero y el último idénticos y el central, más breve, con la función de regreso a la tónica (Rosen, 1983: 43). Ambos solos elaboran material melódico semejante, pero el primero cadencia en el relativo mayor.

Los versos endecasílabos del recitado inicial presentan a un personaje que se expresa como los héroes de la antigüedad en la ópera, justificando el uso del aria en un contexto religioso. Este personaje de corte clásico canta en el aria «por mi en un leño/ has de morir», expresando su gratitud a Jesús cuya redención abarca pasado y futuro, en referencia al texto del responsorio quinto «Hodie genuit Salvatorem saeculi».

\subsection{UN MAESTRO DE CAPILLA, VILLANCICO PARA NAVIDAD DE 1763}

Soler compuso Un maestro de capilla, para ser interpretado como noveno villancico, es decir después del te deum de maitines de Navidad de 1763, cerrando el tercer nocturno. Esta fecha que no consta, se deduce de su posición en el manuscrito pues está anotado entre la cantada Entre al Portal la regia Troya bella para maitines de Navidad de 1763, y el villancico Auras traviesas para maitines de epifanía de 1764 (cuadro 4).

Un maestro de capilla puede calificarse como villancico de chanza, es decir de asunto cómico o satírico con desarrollo dramatizado (Pérez, 2008: 610-613). Como en otros templos, también en El Escorial este tipo de composiciones solían cerrar festivamente el oficio navideño de maitines; además como este último villancico no tenía un responsorio previo, permitía una mayor libertad de asuntos (Sierra, 2001: 146). Esta composición ofrece el tema recurrente de la rivalidad entre poeta y maestro de capilla con ocasión de su necesaria colaboración en la realización de los villancicos. El desarrollo dramático del argumento está perfectamente trazado tanto musical como literariamente; el poeta, orgulloso de su obra, entrega la letra para un nuevo villancico al maestro de capilla quien, sin ambages, expresa su dificultad para poner en solfa un texto tan mediocre, lleno de jerga y de onomatopeyas (Pérez, 2017), haciéndose eco de la opinión ilustrada, vertida ya desde décadas antes por el padre Feijoo (Capdepón, 1993: 41-46). El coro de capilla no toma partido por ninguno de ellos, lo cual constituye una velada sanción a la pasividad de las autoridades eclesiásticas sobre este asunto. La 
moraleja es clara: el discurso musical del villancico evolucionaba, pero sus reiterativos y anquilosados textos lo anclaban al pasado. El asunto debió interesar a la comunidad porque al año siguiente Soler puso música a un villancico titulado Dos maestros de capilla, con los personajes de un maestro anciano y otro moderno (Rubio, 1980: p. 69 n.113); el personaje del poeta reaparece en un villancico de 1767 (p. 75 n. 151) y el maestro de capilla en 1774 (p. 86 n. 222).

El villancico que nos ocupa tiene la peculiaridad de incluir tres partes concertantes: dos vocales para alto y bajo que encarnan los mencionados roles de poeta y maestro de capilla respectivamente, y otra instrumental identificada como «chirimía» pero cuya escritura es más apropiada para el oboe, por los motivos que más adelante se exponen. Las otras cuatro partes vocales aparecen agrupadas como «segundo choro» (SATB), identificando así al coro de capilla. A todo ello se añaden dos partes de violines y una de acompañamiento sin cifrar.

Soler elabora el estribillo a partir de la estructura de aria binaria ya comentada (Rosen, 1983: 43), a la que añade una extensa introducción instrumental con intervenciones concertantes del oboe, anticipando los motivos principales (Cuadro 4). En las coplas reaparecen los motivos del estribillo salvo en las intervenciones a solo de poeta y maestro, esta última a modo de recitativo, que utilizan material nuevo. Falta el texto de las coplas salvo en el inicio de la intervención del coro de capilla (Cuadro 4).

El término castellano «chirimía» se usaba desde el siglo XV para identificar un instrumento de lengüeta doble con tesitura tiple o alto, que formaba parte del conjunto instrumental designado como copla o cobla de ministriles. A lo largo del siglo XVII, chirimías y sacabuches fueron sustituidos en el interior de los templos por cornetas y bajones como acompañamiento de las voces (Escalas, 1999: 59). Sin embargo las chirimías mantuvieron su presencia en el quinteto de ministriles que intervenía en ceremonias al aire libre como procesiones ${ }^{36}$ y faroladas ${ }^{37}$, en cuyo caso los músicos de corneta y bajón se encargaban de tocarlas; así ocurría en Orihuela donde las chirimías ya no tenían dotación en $1678^{38}$ y la de sacabuche se extinguió en $1688^{39}$.

Más allá de cuestiones estéticas, la corneta sustituyó a la chirimía tiple por sus limitaciones para acompañar la polifonía pues estaba en re y precisaba siempre de transporte para que su música no resultara un «punto» o tono alto, tal y como recoge Pablo Nassarre en 1724 (Escalas, 1999:59-61). Las partes obligadas de chirimía en fechas tan tardías como la segunda mitad del siglo XVIII son excepcionales y deben valorarse como un capricho (Virgili, 1987: 102). La chirimía no se menciona en el tratado de Francisco Valls (1742) pero sí el oboe que se había introducido en España a principios del siglo XVIII. Este instrumento recibió inicialmente varias denominaciones y, entre ellas, por su semejanza, también la de chirimía (Virgili, 1987: 101), siendo únicamente los rasgos de la música los que permiten establecer de cual se trata en cada caso.

La chirimía era instrumento transpositor, prefería las tonalidades de re y la que

\footnotetext{
${ }^{36}$ LACO, vol. XVII, fol. 66v, acuerdo de 17-10-1714.

${ }^{37}$ LACO, vol. XVII, fol. 56v, acuerdo de 25-8-1714; fol. 312r, acuerdo de 13-2-1718.

${ }^{38}$ LFCO, sign. 1817, ejercicio 1678-1679. Ya no consta dotación para chirimías.

${ }^{39}$ LFCO, sign. 1823, ejercicio 1687-1688. Última vez que consta partida para sacabuche.
} 
eran más adecuadas y precisaba un registro adaptado a sus posibilidades que abarcaba de re3 a si4 (Escalas, 1999: 61). Tal es el caso de las tres composiciones con dos chirimías conservadas en El Escorial y posteriores a la llegada de Soler en $1752^{40}$.

El tratado de Valls (1742) informa sobre el uso del oboe en las capillas de música. El instrumento tenía un registro comprendido entre do3 y re5, más amplio que la chirimía, no precisaba transporte y sus posibilidades expresivas eran semejantes al violín y, por este motivo, «violines y obuesses en un Lleno de Música tocan una misma parte» (fol. 144v-144r). En caso de que los oboes toquen solos Valls aconseja que «no vayan por lo muy alto del instrumento, porque no chillen, ni por muy bajo tampoco», recomendando no salgan de las cinco líneas del pentagrama «y si fuese necesario añadirle una por arriba» (fol. 144v).

La parte de instrumental de Un maestro de capilla identificada como «chirimía», en tonalidad de fa mayor y con un registro comprendido entre mi3 y do5, excede las posibilidades de este instrumento pero resulta perfectamente realizable por el oboe. La incidencia en el registro que Valls señala de mayor dificultad, revela que esta parte estaba destinada a un intérprete de destreza poco frecuente en el contexto de las capillas hispanas. Tal era el caso de fray Pedro Serra miembro de la capilla de El Escorial entre 1753 y 1766 (Rubio, 1980: p. 25) de cuya habilidad en el oboe y la flauta travesera queda constancia en su panegírico fúnebre. Este texto fue redactado por el propio Padre Soler el 26 de marzo de 1766, con quien le unía una estrecha amistad ${ }^{41}$. Soler escribió además de Un maestro de capilla de ACO 52/4, otras cuatro composiciones con oboe solo u obligado (Capdepón, 1993: 242).

Quizás Soler utilizó el término chirimía por casticismo o por exceso de erudición, pues el francés hautbois designaba tanto la chirimía tiple como el instrumento inventado por Hoteterre y Philidor, que también se designó en España con los galicismos oboe, obué o abué, sin pensar que la voz chirimía también lo había sido de chalemie (Coromines, 2008: 175). El término oboe que fue finalmente adoptado en España, es común a la voz italiana del original francés.

La disposición que utiliza Soler en Un maestro de capilla no es nueva ${ }^{42}$, pero sí su textura: violines y bajo presentan un tratamiento homofónico complementario que podría calificarse como orquestal, sobre el que se impone la parte concertante de oboe. La cuerda asume el motivo de batalla por cuestiones retóricas derivadas del texto, pero

\footnotetext{
${ }^{40}$ Rubio, 1976. Estas tres composiciones son el villancico A festejar a Dios Niño, anónimo de 1761 en re mayor (p.156 n.153), el villancico Menga para cuándo es tu habilidad de Pedro Aranaz (1740-1820), también en re mayor (p. 205 n.402) y, del mismo autor, el responsorio de Navidad Quem vidistis pastores en la mayor (p. 196 n. 360). En las dos de Aranaz se indica que se puede interpretar con oboes lo cual manifiesta el olvido en que había caído la chirimía por esas fechas. También en Archivo de Música de El Escorial, recuperado de https://rbmecat.patrimonionacional.es/ [Consulta 9-7-2020].

${ }^{41}$ Rubio, 1980: p. 25; en p. 139, reproducción de Memorias sepulcrales, vol. II, fol. 401v-405v. El texto de Soler evidencia la amistad que les unió, enfatiza las virtudes de Pedro Serra y permite reconstruir su trayectoria profesional.

42 Pérez, 2008: 705-710, 725-734, 1117. Esta misma disposición es utilizada en composiciones de la propia catedral de Orihuela, realizadas por Mathías Navarro entre 1713 y 1727. En ellas estos instrumentos configuran el coro 1 en textura de cámara (un intérprete por parte), estableciendo la habitual relación concertante policoral barroca con las partes vocales organizadas a su vez en uno o más coros (Pérez, 2016 y 2017b).
} 
la relevancia del oboe no tiene justificación retórica constituyendo una elección particular del compositor, rasgo que concede un singular valor a esta composición.

\subsection{AURAS TRAVIESAS, VILLANCICO PARA EPIFANÍA DE 1764}

Esta composición (Cuadro 5) responde al esquema de villancico con aria o villancico cantata porque combina elementos de ambas formas (Rubio, 1979: 64). En este caso al estribillo sigue una cantata breve que consta de recitativo y aria da capo; tras ella un nuevo recitado que comenta el aria precedente e introduce la repetición del estribillo, todo ello en sol mayor salvo el la menor que inicia el primer recitado y el do mayor de la sección central del aria da capo. El orgánico repite la disposición de $A$ velar, pastores de Belén, pero sin trompas, para vestir un texto alegórico de tono serio en el que el tema de la epifanía solo resulta explícito gracias a los dos recitados.

El título propio informa que fue escrita para epifanía de 1764, constituyendo por el momento, la única composición en romance de Soler para esta solemnidad. La mención de «villancico primero» indica que debía cantarse en el primer nocturno de maitines de epifanía, en cuya ceremonia consta que en El Escorial desde el siglo XVII se cantaban villancicos (Laird, 1993: 197-199). Soler puso música también al himno de epifanía Crudelis Herodes en dos ocasiones distintas; de la primera versión se conservan partes y borrador autógrafo que firma el 31 de diciembre de 1778 (Sierra, 2004c: 188) y de la segunda se conservan varias copias, una de ellas realizada en 1783 (Rubio, 1980: 90).

El estribillo de «estilo madrigalesco» (Valls, 1742: fol. 174r y 174v), se inicia con un pasaje instrumental al que sigue una sección en tradicional textura policoral cuyo texto pregunta sobre el destinatario de las fragancias de la naturaleza, en alusión al incienso y la mirra. La respuesta se desvela en el recitado a dúo. En el aria da capo, cuyo texto carece de mención religiosa alguna, el tenor desarrolla arriesgadas coloraturas y pasajes en amplios arpegios, imitando los instrumentos de metal. Su primera sección presenta estructura de aria binaria con tres ritornelli (Rosen, 1983: 43); la segunda, más breve, repite motivos de la primera en la tonalidad de do mayor. El recitado a dúo que sigue a esta aria $\mathrm{DC}$, permite contextualizar litúrgicamente su contenido y enlazar con la repetición total del estribillo.

\subsection{MAS $A Y$ QUE $A L$ ECO, CANTADA AL SANTÍSIMO SACRAMENTO DE 1779}

La cantada Mas ay que al eco (Cuadro 7) para tenor, violines y acompañamiento, está dedicada al Santísimo Sacramento y desarrolla el tema del Buen Pastor: Jesús interpela a la oveja perdida para que regrese al rebaño, pues fuera le aguarda el peligro del lobo. Esta cantada fue compuesta en 1779 y repite la misma estructura de cantada breve de Entre al Portal la regia Troya bella contenida en este mismo manuscrito y escrita 15 años antes.

La primera sección (A) se desarrolla como las anteriores según el esquema de aria binaria (Rosen, 1983: 43). La sección A del aria está incompleta pues el fol. 15r se rasgó con limpieza a la altura de la pauta 13, lo que denota intencionalidad y, por ello, faltan unos nueve compases del segundo solo y otros quince del ritornello final. La 
sección central (b) que se anotó en el fol. $15 \mathrm{v}$ está completa y contrasta vivamente con la primera, especialmente por el diseño de movimiento perpetuo que realizan los violines para ilustrar la perenne acechanza del lobo, símbolo del mal.

El texto y la música de esta aria escrita en 1779, especialmente de su sección central («Ven pues tu amado / levanta el cayado / contra el insulto /del lobo feroz»), tiene un significado especial en relación con los acontecimientos que protagonizó Soler durante el periodo de 1777 a 1779, que José Sierra Pérez califica como la «Crisis del Padre Soler» con cuyo desarrollo, posiblemente, esté relacionado este manuscrito.

\section{AH CHE DISSI INFELICE!, «ULTIMA SCENA DE LA OPERA DI LA DIDONE»}

Samuel Rubio (1980) identifica 22 títulos de obra vocal profana del Padre Soler (p. 151), todos ellos en el Escorial y destinados a amenizar «la representación escénica de algún auto o comedia» (p. 38). José Sierra (1987) concreta que este repertorio fue realizado para la actividad teatral del propio colegio y seminario jerónimo hasta su prohibición en 1765, salvo dos pequeñas loas de 1772 y 1783 (p. 570-571). Junto a este teatro escolar, la presencia temporal de la familia real hizo que el regio monasterio también fuera escenario de espectáculos teatrales cortesanos a cargo de compañías profesionales en los que se incluían óperas ${ }^{43}$. Por ello y ante el silencio del archivo escurialense, José Sierra (1983) se preguntaba si el padre Soler pudo haberse interesado por la ópera (p. 30). El contenido del manuscrito ACO 52/4 permite contestar afirmativamente.

\subsection{IDENTIFICACIÓN DEL LIBRETO Y DE SU AUTOR}

Tal y como informa su título propio, ;Ah che dissi infelice! es el inicio del monólogo de Dido que constituye la última escena de Didone abbandonata, libreto en tres actos escrito por Pietro Metastasio que aborda la truncada historia de amor entre Dido y Eneas que narra el libro IV de la Eneida de Virgilio (Martín, 2012: 355). Domenico Natale Sarro (Trani 1679-Nápoles 1744), fue el primero que le puso música en una ópera homónima estrenada el 1 de febrero1724 en el Teatro de San Bartolomé de Nápoles ${ }^{44}$. Este libreto gozó de gran estima pues durante el siglo XVIII fue musicalizado para teatros de toda Europa por más de sesenta compositores, entre ellos Albinoni, Hasse, Haendel, Porpora o Paisiello, (Rodríguez, 2015: 81).

La ópera italiana y los melodramas de Pietro Metastasio en particular, tuvieron en Carlo Broschi, «Il Farinelli», un gran valedor en España desde su llegada a la corte en 1737 (p. 349). Concretamente la Didone de Metastasio incide en las virtudes morales y patrióticas contribuyendo a mantener vivo el interés por un personaje que, en el caso de las letras hispánicas, se remontaba al siglo XVI (pp. 349-350, 355).

43 Sierra, 1983: 7-15. Soler coincidió en el monasterio en 1755 con el compositor de ópera Nicola Conforto y en 1756 con el cantante Joaquín Conti llamado Gizziello.

${ }^{44}$ Recuperado de http://www.progettometastasio.it/testi/DIDONE|P1 y

http://www.italianopera.org/compositori/S/c220466.htm [Consulta 13-6-2020]. 
En vida de Soler, este drama se puso en escena en coliseos de Madrid y Barcelona en cuatro ocasiones. Dido abbandonata en italiano, con música de Giuseppe Scolari compositor nacido en Vicenza hacia 1720 y fallecido posiblemente en Lisboa hacia 1774 (Weiss, 1992: vol.4, p.272), se estrenó el 30 de mayo de 1752 en el Teatro de Santa Cruz de Barcelona para conmemorar la onomástica de Fernando VI ${ }^{45}$ con una escenografía muy vistosa realizada por Francesc Tramulles ${ }^{46}$. Ese mismo año con ocasión del cumpleaños de Fernando VI, se presentó en el coliseo del Buen Retiro el 23 de septiembre 1752 otra Dido abbandonata con música de Baldassare Galuppi (Burano 1706-Venecia 1785) $)^{47}$. Al año siguiente, el 4 de noviembre de 1753 el Teatro de Santa Cruz de Barcelona repuso la versión de Scolari con motivo de la onomástica del futuro Carlos III ${ }^{48}$. En 1757 se estrenó en Madrid la comedia El valiente Eneas, por otro título Dido abandonada de Joseph Ibáñez y Gassia, que es una versión en castellano de la Didone de Metastasio cuya música se desconoce (Rodríguez, 2015: 82).

\subsection{LA ASCENSIÓN DEL PADRE SOLER}

Ah che dissi infelice! carece de fecha en el manuscrito ACO 52/4 pero se encuentra anotada entre dos composiciones datadas respectivamente en 1764 y 1779, arco temporal muy relevante en la biografía de Antonio Soler. Esther Morales Cañadas (2014) califica las etapas 1760-1766 y 1766-1778 como «Años pretensiosos» y «La etapa musical consolidada» respectivamente (p. 51, 69); este panorama se interrumpe bruscamente en 1778 cuando tiene lugar un episodio que José Sierra (2004) califica como «La crisis del Padre Soler».

Soler aprovechó las Jornadas o estancia otoñal de la corte en El Escorial para ampliar su actividad más allá de la música religiosa. El primer paso lo dio diez años después de llegar al Monasterio cuando, ya maestro de capilla, publicó en $1762 \mathrm{La}$ Llave de la Modulación, obra teórica que incluye ocho preludios y le dio a conocer en todo el ámbito hispano (Gonsálvez, 1995: 38). El segundo paso fue entrar en contacto con personajes de la corte, como Pedro de Alcántara Alonso Pérez de Guzmán el Bueno XIV Duque de Medina Sidonia (1724-1779), personaje erudito e intérprete de clave con quien Soler mantuvo correspondencia entre 1761 y 1771. Si bien finalmente él no fue artífice de sus deseos, estas epístolas manifiestan una relación cercana que le permitiría introducirse en el círculo musical áulico controlado por músicos italianos (Hollis, 2000: 222-223). La correspondencia con el Duque revela que Soler a pesar de su condición de religioso, tuvo relación directa con muchos de estos músicos italianos como el compositor de ópera Luigi Marescalchi (Bolonia 1745-1805) ${ }^{49}$, alumno del padre Martini que estuvo en Madrid en 1765 y en 1766 (Hollis, 2000: 228). Marescalchi

45 Alier, 1990: 123-124. El teatro de santa Cruz estuvo arrendado durante el periodo 1750-1753 por Nicola Setaro quien contaba con Scolari como maestro de capilla (como consta en la información del libreto editado para la ocasión) de un elenco formado por cantantes italianos. La obra tuvo doce sesiones en las cuales se usaron fuegos de artificio. Esta información también recuperada en http://www.italianopera.org/compositori/S/c2206001.htm [Consulta 13-6-2020].

${ }^{46}$ Bravo, 1986: 40-44. También Alcolea, 1961-1962: 176. El libreto se imprimió en Imprenta Mojados, recuperado de http://www.progettometastasio.it/testi/DIDONE|P3 [Consulta 13-6-2020].

${ }^{47}$ Rodríguez, 2015: 81; Monson, 1992: vol.2, 337-341.

${ }^{48}$ Alier, 1990: 134, 139. También se publicó libreto impreso el 21 de octubre de 1753 de esta reposición que se presentó con ocasión de la onomástica de Carlos Rey de Nápoles y hermano de Fernando VI. La primera representación debió ser el 4 de noviembre de 1753, día de san Carlos.

${ }^{49}$ Recuperado de http://www.italianopera.org/compositori/M/c219416.htm [Consulta 16-9-2018]. 
aparece mencionado en las cartas de 1766 y 1767 en relación a Pedro Santamant (1752?), alumno de Soler y protegido del Duque (p. 228-238).

En junio de 1765 Soler inició correspondencia con el padre Martini (Kastner, 1957: 237-238) y, ese mismo año, coincidiendo con la boda de los príncipes de Asturias, Soler dedicó a María Luisa de Parma una sonata que pretendía tocar ante ella (Hollis, 2000: 226). En 1766 el infante don Gabriel cumplió 14 años e inició sus academias de música en El Escorial (Morales, 2014: 69-70, 74). Durante los meses de otoño de 1766, Soler progresó en su acercamiento a las reales personas tal y como revela una carta que escribe a Martini el 30 de noviembre de ese mismo año ${ }^{50}$.

En 1767 escribió un motete para un concurso en París por cuyo envío y recepción preguntó en diciembre al Duque de Medina Sidonia (Hollis, 2000: 230). Finalmente, en 1768 consiguió la tutela musical del infante don Gabriel durante las Jornadas en San Lorenzo, gracias a la mediación de Nicola Conforto (Nápoles 1718Aranjuez 1773), a quien conocía desde 1755 (Sierra, 1983: 30). Soler mantenía desde 1766 una relación amistad con don Gabriel (Rubio, 1980: 23) y para él escribió toda su música instrumental. Entre ella destacan sus XXVII sonatas para clave que entregó el 14 de febrero de 1772 en El Escorial a lord Fitzwilliam (Rubio, 1980: p. 47) para su edición en Londres donde fueron impresas ese mismo año (Gonsálvez, 1995:34).

Pero los éxitos de Soler provocaban también el escándalo de algunos de sus hermanos en la regla como fray Julián Villegas, designado prior el 13 de febrero de 1773. Fray Villegas que era persona de confianza de Carlos III, ocupó este cargo hasta su muerte en 1781 manifestando un gran rigor y celo por la regla, siendo especialmente crítico e intransigente en el trato con los seglares que, durante las Jornadas, era inevitable (Campos, 2004:105-110). En este contexto los músicos eran necesariamente vulnerables y, especialmente, Soler por su cargo de tutor musical del Infante. Este contacto de Soler con la corte se extendió a la Casita del Infante concluida en 1772 (Rubio, Samuel. 1980: 23-24) y más allá de la sombra de los muros escurialenses, cuando Soler acompañó a la familia real en las jornadas de Aranjuez de 1775 y de El Pardo de 1777 (Sierra, 2004a: 14-16).

\section{3 «LA CRISIS DEL PADRE SOLER» Y EL MANUSCRITO ACO 52/4}

Algo ocurrió en los meses siguientes que sumió a Soler en un profundo desasosiego hasta el punto que expresó sus inquietudes al infante, al rey, al Padre Montemolín General de la Orden y, finalmente, solicitó formalmente el traslado a los Jerónimos de Granada. El 24 de febrero de febrero de 1778, fray Juan de la Asunción, prior de San Jerónimo de Granada informaba al Padre Montemolín, que Soler había solicitado traslado a la ciudad andaluza, que los motivos que alegaba eran justos y que esperaba contar con el beneplácito del rey; él no ponía objeción para el traslado pues el interesado se hallaba «en el mayor conflicto, y tal vez, aunque como considerado, expuesto a un ruidoso estrépito, nada favorable» para la comunidad de El Escorial (Campos, 2004:127-128).

\footnotetext{
${ }^{50}$ Kastner, 1957: 238. «Non ho possuto fin de ora avanzare la mia fatica del Canto Ecclesiastico in proseguirne l'opera, si p. l'ocupazione avuta nella dimora della corte in questo Real Monastero, essendo stato occupatissimo p. le Persone Reali, si ancora p. le funzioni solite a farsi nelle venture Sante Feste, nella composizione di cio che noi chiamamo Villancicos nel nro coro».
} 
Montemolín informó el 14 de marzo de 1778 al Padre Villegas, prior de El Escorial, sobre los deseos de Soler y la buena disposición a acogerlo en Granada. Además, considerando que como otras veces todo pasaría y con el deseo de solucionar el problema, consideraba importante averiguar «los poderosos motivos que tanto exagera el Padre Soler» (p. 128-129).

El Prior Villegas elevó al rey la solicitud de traslado, pero también inició un proceso sumario que concluyó encontrando reo a Soler de los sucesos que él mismo había dado a conocer. El proceso fue duro para Soler quien durante su transcurso expresó su intención de solicitar la secularización (p. 140, 145). El rey requirió información antes de decidir el traslado de Soler y, aunque el padre general informó que no había motivos para impedir el traslado de Soler a Granada, pesó más la opinión negativa del Prior Villegas. Éste alegaba que todo habían sido imaginaciones de Soler quien, arrepentido de su actitud pasada, ya no deseaba marchar; alegó además interesadamente que el monasterio sufriría gran daño al verse privado de su habilidad, conseguida precisamente entre sus claustros (p. 150).

La documentación relativa a este asunto se conserva $\mathrm{y}$, aunque falta precisamente la declaración de los motivos que aducía Soler para su traslado, revela que éste se sentía rechazado y acosado por la comunidad hasta el punto de temer por su vida. Soler no consiguió sus aspiraciones, fundamentalmente por la oposición del Prior Villegas quien censuraba abiertamente la relación de algunos monjes con la corte y temía que la comunidad escurialense quedara en evidencia si el músico dejaba el monasterio (p. 125, 136-145). La documentación sobre este asunto termina el 17 de octubre de 1778, justo cuando empezaba la Jornada Real en El Escorial (p. 158-164). Aunque Soler no consiguió liberarse de su celda escurialense, mantuvo el contacto con la familia real durante los cuatro años que le quedaban de vida (Sierra, 2004a: 16).

José Sierra (2004a) plantea que la obsesión de Villegas por conseguir la prohibición de representar óperas en los reales sitios, podría estar relacionada con el proceso a Soler a pesar de que no quede constancia en El Escorial de que hubiera escrito ópera para la corte (pp. 15-16). El manuscrito de Orihuela revela que Soler se interesó efectivamente por la ópera pues contiene música para el final de Didone abbandonata de Metastasio, lo cual ofrece un factor nuevo para la mencionada crisis. Es posible que el deseo del padre Soler por secularizarse esté relacionado con el deseo de ampliar su horizonte creativo, pues en la España de Carlos III, la ópera no era considerada adecuada para un eclesiástico como opinaba Villegas.

Soler ya había dado muestras en la música en romance de su capacidad para manejar el recitativo y especialmente el aria; sirvan como ejemplo las arias anotadas en este mismo manuscrito. El contacto con la corte propició su interés por la ópera y por las posibilidades que le ofrecía. La audición pública de Ah che dissi infelice!, si se produjo, pudo tener el mismo selecto auditorio que las funciones de El Escorial o las academias del Infante don Gabriel, pero también pudo despertar las iras de su riguroso prior.

Soler, un monje jerónimo brillaba con luz propia y gozaba del aprecio de la familia real y, por ello, se desenvolvía en ambientes escandalosos para Villegas. Éste no podía oponerse a su patrono el Rey, pero tenía potestad sobre Soler en cuestiones 
religiosas (Campos, 2004: 150) y, el proceso sumario que inició contra él, revela que encontró un motivo para convertirlo en objeto de sus iras y ejemplo para el resto de la comunidad. Soler debió prever los problemas que como religioso podía tener si su comunidad sabía que estaba poniendo música a un texto operístico y, por ello, ocultó el borrador de este proyecto en papeles que había utilizado para otras composiciones como es el caso del manuscrito de Orihuela. Es posible que la cavatina que falta la compusiera primero en otro lugar y luego completó en este cuadernillo los recitativos que la enmarcan.

\subsection{TRANSCRIPCIÓN Y DESCRIPCIÓN DEL TEXTO}

Soler debió considerar que no pecaba de frívolo al escoger Didone abbandonata de Metastasio pues había sido representada con motivo de efemérides monárquicas como es el caso de las ya citadas de Madrid y Barcelona de 1753 y 1754. Los libretos de estas versiones de Gallupi y Scolari fueron impresos respectivamente por Mojados ${ }^{51}$ y por Paolo Campíns (Alier 1990: 123). No se conoce el paradero del segundo pero sí un ejemplar de la reposición de la Didone de Scolari en Ferrara en 1763, custodiado en la Biblioteca del Congreso de Estados Unidos ${ }^{52}$. Es factible que Soler tuviera acceso a los libretos de ambas versiones pues fueron las más cercanas geográfica y temporalmente, pero pudo disponer de otros gracias a sus amistades en la corte como el Duque de Medina Sidonia (Hollis, 2000: 222).

El libreto de la Didone que Giuseppe Scolari presentó en Ferrara en 1763, tiene ciertos elementos que coinciden con el texto anotado en el borrador de Soler y, por ello, se ha utilizado para completar la transcripción de Ah che dissi infelice!, "Ultima scena de la opera di la Didone» (Cuadro 8). El texto que anotó Soler en el borrador de Orihuela presenta incorrecciones léxicas propias de alguien que no domina el italiano ${ }^{53}$.

\subsection{TRANSCRIPCIÓN (ANEXO I) Y DESCRIPCIÓN DE LA MÚSICA}

Se desconoce la música de Scolari para Didone abbandonata, pero las versiones de Soler y Gallupi coinciden en la organización a partir del metro en tres secciones y en el planteamiento armónico global (la escena se abre y se cierra en la misma tonalidad). El metro permite dividir musicalmente esta escena en tres partes: dos recitados de metro desigual pero iniciados con sendos versos heroicos, enmarcan una estrofa de cuatro versos heptasílabos (Cuadro 8). Para la sección central Gallupi escoge una cavata (aria binaria con tres ritornelli) de cierta envergadura ${ }^{54}$ y Soler una cavatina. Esta elección incide en el desarrollo dramático de la escena del mismo modo que otras versiones de Didone como la compuesta para París en 1753 por Johann Adolph Hasse ${ }^{55}$.

\footnotetext{
${ }^{51}$ Recuperado de http://www.progettometastasio.it/testi/DIDONE|P3 [Consulta 13-6-2020].

52 Recuperado de http://hdl.loc.gov/loc.music/musschatz.18173 [Consulta 13-6-2019].

${ }^{53}$ Kastner (1957) destaca que el texto en italiano de las cartas de Soler tampoco es correcto (p. 236-273).

54 Gallupi, B. (s. f.). Didone abbandonata [manuscrito], fol. 58v-65v. Biblioteca del Conservatorio de Nápoles. Recuperado de http://hz.imslp.info/files/imglnks/usimg/5/57/IMSLP362972-PMLP586004-Rari_6.5.20 [Consulta 04-06-2019].

${ }_{55}$ Hasse, J. A. (1753). Didone abbandonata [manuscrito]p. 111-112. Biblioteca del Conservatorio de París. Recuperado de http://hz.imslp.info/files/imglnks/usimg/8/8c/IMSLP433035-PMLP44786--RES1351-_Didone_1753_03.pdf [Consulta 04-06-2019].
} 
En el manuscrito ACO 52/4 Soler solo apuntó el último compás de la cavatina en mi bemol mayor, para enlazar con el segundo recitativo que empieza en anacrusa. Esto induce a pensar que Soler ya había realizado previamente la cavatina que había anotado en otro lugar. También en mi bemol mayor se desarrolla el recitativo y aria «Siento ay de mi» de la cantada Cuanto descubro en ti del Padre Soler conservada en la catedral de Orihuela ${ }^{56}$. La letra de esta composición presenta notables coincidencias léxicas con la estrofa en italiano de la cavatina extraviada; estas coincidencias permiten una reconstrucción plausible de la cavatina a partir de esta aria (Berná, 2020)

Soler distingue como «Reci[ta]do/Allegro» el recitado previo a la cavatina y como «Reci[tati]vo», el posterior. Es posible que esta distinción sea banal pues por lo demás uno y otro comparten incluso motivos musicales. Para elaborar sendas secciones, Soler se ajusta a la opinión y procedimientos del tratado de Francisco Valls (1742). Éste recomienda que en el recitado se siga «una relación de consonancia y disonancias, sin atarse a reglas ni preceptos músicos» pero que «la salida sea especie consonante, aun imperfecta, que de esta manera se comprehendería es harmónico lo que se recita» (fol. 195r). Sobre este principio racional Soler, al igual que Gallupi, plantea el desarrollo harmónico global de toda la escena que abre y cierra un mismo acorde que le sirve de marco tonal. Soler escoge para ello la tonalidad de Mi bemol siguiendo la opinión de Valls de que un «tono muy accidental por blando» (armaduras con bemoles), es más apropiado «para conmover a lástima» (fol. 195r-195v).

Las ideas desarrolladas en los recitativos permiten dividir ambos en dos secciones, diferenciadas tanto en su desarrollo harmónico como en los motivos musicales que ilustran los afectos (Cuadro 8). Estos procesos retóricos son especialmente evidentes en el diseño de las partes de violines, pues el perfil de la parte vocal está condicionado por la entonación del idioma.

\section{CONCLUSIONES}

Hay factores suficientes que permiten afirmar que el manuscrito ACO 52/4 es un borrador autógrafo del Padre Soler. En primer lugar, utiliza un papel que se usó en El Escorial durante las décadas centrales del siglo XVIII; en segundo lugar, su grafía y firma presentan los mismos rasgos que otros manuscritos conservados en El Escorial y considerados autógrafos; en tercer lugar, las seis composiciones en castellano en él anotadas, están relacionadas con el ceremonial de El Escorial y son resultado de la actividad de Soler como maestro de su capilla de música. La composición en italiano que figura anotada en sexto lugar, no está vinculada con su actividad como maestro de capilla sino con su intención de ampliar su actividad creativa fuera del ámbito religioso. Esta composición resulta especialmente relevante porque puede estar relacionada con los acontecimientos que protagonizó Soler durante el año 1778.

Los primeros cuatro títulos del manuscrito ACO 52/4 estaban destinados a ser interpretados por la capilla de El Escorial en el transcurso de los maitines de Navidad

56 Climent 1986: 246, número 1632 que corresponde a la signatura 54/26; la descripción de estos materiales en nota 1 . 
del año 1763, bicentenario de la colocación de su primera piedra, cuyos actos conmemorativos tuvieron lugar el 29 y 30 de agosto de ese año y que recogió por escrito el propio Antonio Soler (Sierra 2004b: 55-60). Los tres títulos restantes del manuscrito llenan un notable vacío en la obra del Padre Soler: por el momento Auras traviesas es la única composición en romance de Soler dedicada a la Epifanía, Ah che dissi infelice! su única musicalización de un fragmento de un texto operístico y Mas ay que el eco, fechada en 1779, la única composición en castellano de los últimos cinco años de su vida (Capdepón, 1993: 54).

Además, con ocasión de analizar el contenido de este manuscrito, se ha establecido el léxico que en la época se utilizaba a partir de las propias fuentes musicales oriolanas y escurialenses. Estos términos son borrador, como sinónimo de partitura, que podía ser original o copia con el mismo significado actual; guion que tenía el doble significado de reducción para dirigir o reseña de los íncipits como información de archivo; hoja y plana como sinónimos de folio y página respectivamente.

Se desconoce el motivo por el que este manuscrito de Soler se archivó como número 4 de la carpeta o legajo 52 en la catedral de Orihuela donde también hay otros manuscritos de compositores vinculados a El Escorial, como Joseph Falguera y Monserrate. Cabe mencionar dos hipótesis. Joaquín López, maestro de capilla en Orihuela entre 1785 y 1813, abandonó su puesto en 1790 y, durante unos meses, ejerció el magisterio del Convento de la Encarnación de Madrid (Pérez, 2013: 153-154). Durante esta estancia en la corte, Joaquín López se pudo hacer con materiales procedentes del archivo particular de Soler que, tras su muerte, quedaran en poder de su familia o circularan en los ambientes musicales (Hollis, 2000: 223) y, finalmente, el manuscrito que nos ocupa terminó en la catedral de Orihuela. Cabe también la posibilidad de que llegara a Orihuela en el mismo lote de inventario que las obras de Joseph Falguera y Monserrate cuando éste falleció en 1824. Los otros dos títulos de Soler que se conservan en el archivo de la catedral de Orihuela presentan una referencia numérica semejante a las descritas para las obras de Falguera posiblemente producto de un inventario que, sin embargo, no tiene el manuscrito ACO 52/4.

\section{BIBLIOGRAFÍA}

Alcolea Gil, S. (1961-1962). La pintura en Barcelona durante el siglo XVIII. II Parte Diccionario Biográfico. Anales y Boletín de los Museos de arte de Barcelona, 15, 11263.

Alier Aixalá, R. (1990). L'òpera a Barcelona: Orígens, desenvolupament i consolidació de l'òpera com a espectacle teatral a la Barcelona del segle XVIII. Barcelona, España: Institutd'Estudis Cataláns.

Belina, L. y Tessarolo, L. Progetto Metastasio (s.f.). Recuperado el 13 de junio de 2020 de http://www.progettometastasio.it

Berná Pérez, J. (2020). Transcripción y reconstrucción de Ah che dissi infelice! última escena de la Didone del Padre Antonio Soler a partir de ACO 52/4.6 y 54/26. Material no publicado.

Bianchini, L. y Trombetta, A. (s.f.) ItalianOpera. Recuperado el 13 de junio de 2020 de http://www.italianopera.org/compositori

Bravo,I. (2004). L'escenografia catalana. Barcelona, España: Diputació de Barcelona.

Campos, F. J. (2004). La crisis del P. Antonio Soler, OSH (1778). En J. Sierra Pérez (Ed.), Vida 
y Crisis del Padre Antonio Soler (1729-1783). Madrid, España: Editorial Alpuerto, 105164.

Capdepón Verdú,P. (1993). El padre Antonio Soler (1729-1763) y el cultivo del villancico en El Escorial. Real Monasterio de El Escorial, Madrid, España: Ediciones Escurialenses.

Carreras, J. J. (2000). Las cantatas españolas de la colección Mackworth de Cardiff. En M. Boyd y J. J. Carreras (Eds.), La música en España en el siglo XVIII.Madrid, España: Cambridge University Press, 127-144

Cavia Naya,M. V. (1999-2002). Falguera, José. En E. Casares (ed.), Diccionario de la música española e hispanoamericana. Madrid: SGAE, Vol. 4, 894.

Climent Barber,J. (1986). Fondos musicales de la Región Valenciana. IV: Catedral de Orihuela. Valencia, España: Instituto Alfonso el Magnánimo.

Climent Barber,J. (1999-2002a). Grana, Francisco. En E. Casares (ed.), Diccionario de la música española e hispanoamericana. Madrid: SGAE, Vol. 5, 826.

Climent Barber,J. (1999-2002b). Molina, Antonio (I). En E. Casares (ed.), Diccionario de la música española e hispanoamericana. Madrid: SGAE, Vol. 7, 641.

Coromines,J. (2008). Breve diccionario etimológico de la lengua castellana. Madrid: RBA.

Escalas,R., Gibiat, V., \& Barjau, A. (1999). La colección de instrumentos renacentistas de la catedral de Salamanca: estudio organológico multidisciplinar. Revista de Musicología, 22 (1), 49-90.

Gonsálvez Lara, C. J. (1995). La edición musical española hasta 1936. Madrid (España): Asociación Española de Documentación Musical.

Hollis, G. T. (2000). El diablo vestido de fraile: a propósito de alguna correspondencia inédita del padre Soler. En M. Boyd y J. J. Carreras (Eds.), La música en España en el siglo XVIII. Madrid: Cambridge University Press, 219-234.

Kastner, S. (1957). Algunas cartas del P. Antonio Soler dirigidas al P. Giambattista Martini. Anuario Musical, 12, 235-240.

Laird, Paul R. (1993). Los villancicos del siglo XVII en el Monasterio de El Escorial. En F. J. Campos (Ed.) La Música en el Monasterio de El Escorial. Real Monasterio de El Escorial, Madrid, España: Ediciones Escurialenses, 169-234.

Libro de Actas Capitulares de la Catedral de Orihuela (LACO), Vol. 17, manuscrito depositado en Archivo de la Catedral de Orihuela (ACO).

Libro de Fábrica de la Catedral de Orihuela (LFCO), sign. 1817, ejercicio 1678-1679, manuscrito depositado en Archivo Histórico de Orihuela (AHO).

Libro de Fábrica de la Catedral de Orihuela (LFCO), sign. 1823, ejercicio 1687-1688, manuscrito depositado en Archivo Histórico de Orihuela (AHO).

López García, J. L. (1983). Transcripción de cinco villancicos del Padre Soler del manuscrito 52/4 de ACO: A velar pastores de Belén; Una zagaleja; Entre al Portal la regia Troya bella; Auras traviesas; Un maestro de capilla. Material no publicado.

Martín Puente, C. (2012) La historia de Roma en la obra dramática de Ramón de la Cruz y Vicente Rodríguez de Arellano. Cuadernos de Filología Clásica. Estudios Latinos, 32 (2), 347-370.

Monson,D. E. (1992). Galuppi, Baldasarre. En S. Sadie (Ed.), The New Grove. Dictionary of Opera. London: Macmillan Press Limited, Vol. 2, 337-341.

Morales Cañadas, E. (2014). Antonio Soler, un visionario ilustrado. Intento musical y biográfico razonado. Munich, Alemania: Akademische Verlagsgemeinschatt München.

Moreno, C. (manuscrito 1909). Inventario. Archivo de música. Propiedad de la santa Iglesia Catedral de Orihuela. Manuscrito realizado en 1909 depositado en el Archivo de la Catedral de Orihuela (ACO), sin signatura.

Pérez Berná, J. (2008) La Capilla de Música de la Catedral de Orihuela: las composiciones en romance de Mathias Navarro (ca. 1666-1727) (Tesis doctoral). Recuperada de http://hdl.handle.net/10347/2404

Pérez Berná, J. (05 de abril de 2016). Matías Navarro (ca. 1666-1727), "Qué nuevas armonías" villancico de kalenda de Navidad. [Archivo de vídeo]. Recuperado de 
https://youtu.be/WkjH-KDFYlc

Pérez Berná, J. (2016). Transcripción de Un maestro de capilla del Padre Antonio Soler a partir de ACO 52/4.4. Material no publicado.

Pérez Berná, J. (05 de mayo de 2017). Matías Navarro (ca. 1666-1727), "Marche el campo" villancico al $\mathrm{Sm}^{\circ}$ Sacramento. [Archivo de vídeo]. Recuperado de https://youtu.be/ls8anOz0J0Q

Pérez Berná, J. (07 de julio de 2017). P. Antonio Soler (1729-1783) "Un maestro de Capilla", villancico para Navidad de 1763. [Archivo de vídeo]. Recuperado de https://youtu.be/LA-mkY0yXd4

Pérez Berná, P. (2013) Del silencio a la voz. Joaquín López maestro de capilla de la catedral de Orihuela (1785-1813) (Tesis doctoral inédita). Universidad de Valencia, Valencia, España.

Rodríguez Alonso, M. V. (2015). De la Ilustración al Romanticismo: teatro y espectáculos italianos en España a caballo entre los siglos XVIII y XIX a través de Pietro Metastasio y Vittorio Alfieri (Tesis doctoral). Recuperada de http://hdl.handle.net/10481/40314

Rosen, C. (1987). Las formas de sonata. Barcelona, España: Editorial Labor.

Rubio, S. (1976). Catálogo del Archivo de Música de San Lorenzo el Real de El Escorial. Cuenca, España: Instituto de Música Religiosa de la Diputación Provincial de Cuenca.

Rubio, S. (1979). Forma del villancico polifónico desde el siglo XV al XVIII, Cuenca, España: Instituto de Música Religiosa.

Rubio, S. (1980). Antonio Soler Catálogo Crítico. Cuenca, España: Instituto de Música Religiosa de la Diputación Provincial de Cuenca.

Serna Serna, A., López García, J. L. (1980). Microfilmación del Archivo Musical de la catedral de Orihuela. Material no publicado.

Sierra Pérez, J. (1983). Introducción. En A. Soler, I Música escénica. Antonio Soler (17291783) [música impresa]. J. Sierra Pérez (estudio y transcripción). El Escorial, Madrid (España): Ediciones Escurialenses, Patrimonio Nacional, 7-31.

Sierra Pérez, J. (1987). La música escénica en El Escorial. El Padre Antonio Soler y la tradición calderoniana. Revista de la Sociedad Española de Musicología, 10 (2),563-580.

Sierra Pérez, J. (2001). Presencia del castellano en la liturgia latina: el villancico. Nassarre, 18(1-2), 115-154.

Sierra Pérez, J. (2004a). Introducción. En Autor (Ed.), Vida y Crisis del Padre Antonio Soler (1729-1783). Madrid: Editorial Alpuerto, 7-16.

Sierra Pérez, J. (2004b). Relación de las fiestas con que esta Comunidad solemnizó su segundo Centenario en este año de mil setecientos sesenta y tres. Escrito de Antonio Soler. En Autor (Ed.), Vida y Crisis del Padre Antonio Soler (1729-1783). Documentos. Madrid: Editorial Alpuerto, 55-60.

Sierra Pérez, J. (2004c). Breve nota bibliográfica y Apéndices 1 y 2. En Autor (Ed.), Vida y Crisis del Padre Antonio Soler (1729-1783). Madrid: Editorial Alpuerto, 177-194.

Soliva Sánchez, M. (2016). La flor de lis como símbolo heráldico localizada en documentos manuscritos valencianos de los siglos XVII-XVIII (Real Colegio-Seminario del Corpus Christi de Valencia y Archivo Municipal de Alicante). Boletín de la Academia Valenciana de Genealogía y Heráldica21, 21-30.

Valls, F. (1742). Mapa Armónico Práctico (manuscrito). Edición facsímil: J. Pavía i Simó, (Edit.). Francesc Valls: Mapa Armónico Práctico (1742ª) (2002). Barcelona, España: CSIC, Institución Milá i Fontanals, Departamento de Musicología.

Virgili Blanquet, M. A. (1987). Voces e instrumentos en la música española del siglo XVIII. Nassarre, 3 (2), 95-106.

Weiss, P. (1992). Scolari, Giuseppe. En S. Sadie (Ed.), The New Grove. Dictionary of Opera. London: Macmillan Press Limited, Vol. 4, 272. 


\section{CUADRO 1. FICHA DE CATALOGACIÓN DE ACO 52/4.1}

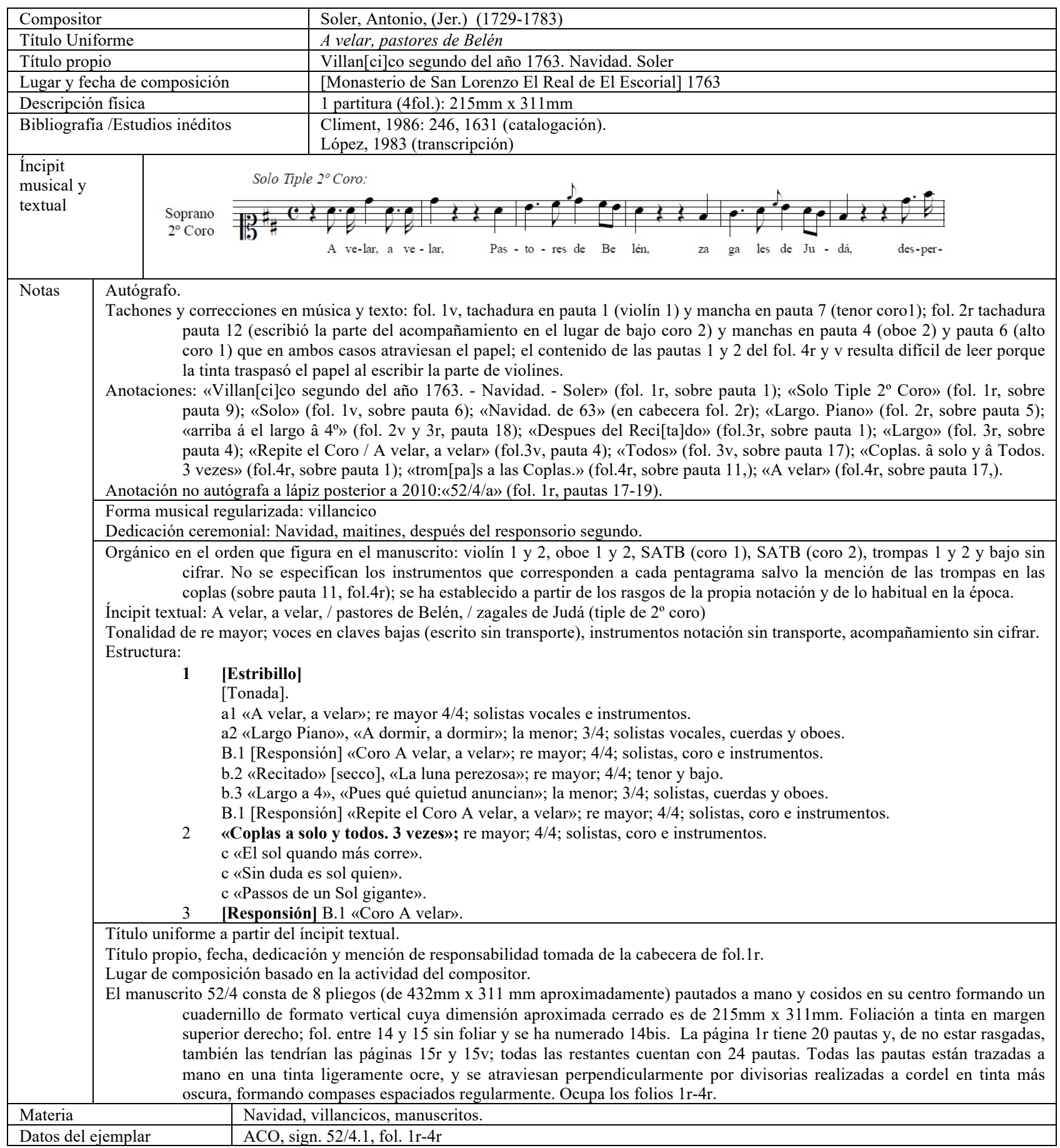




\section{CUADRO 2. FICHA DE CATALOGACIÓN DE ACO 52/4.2}

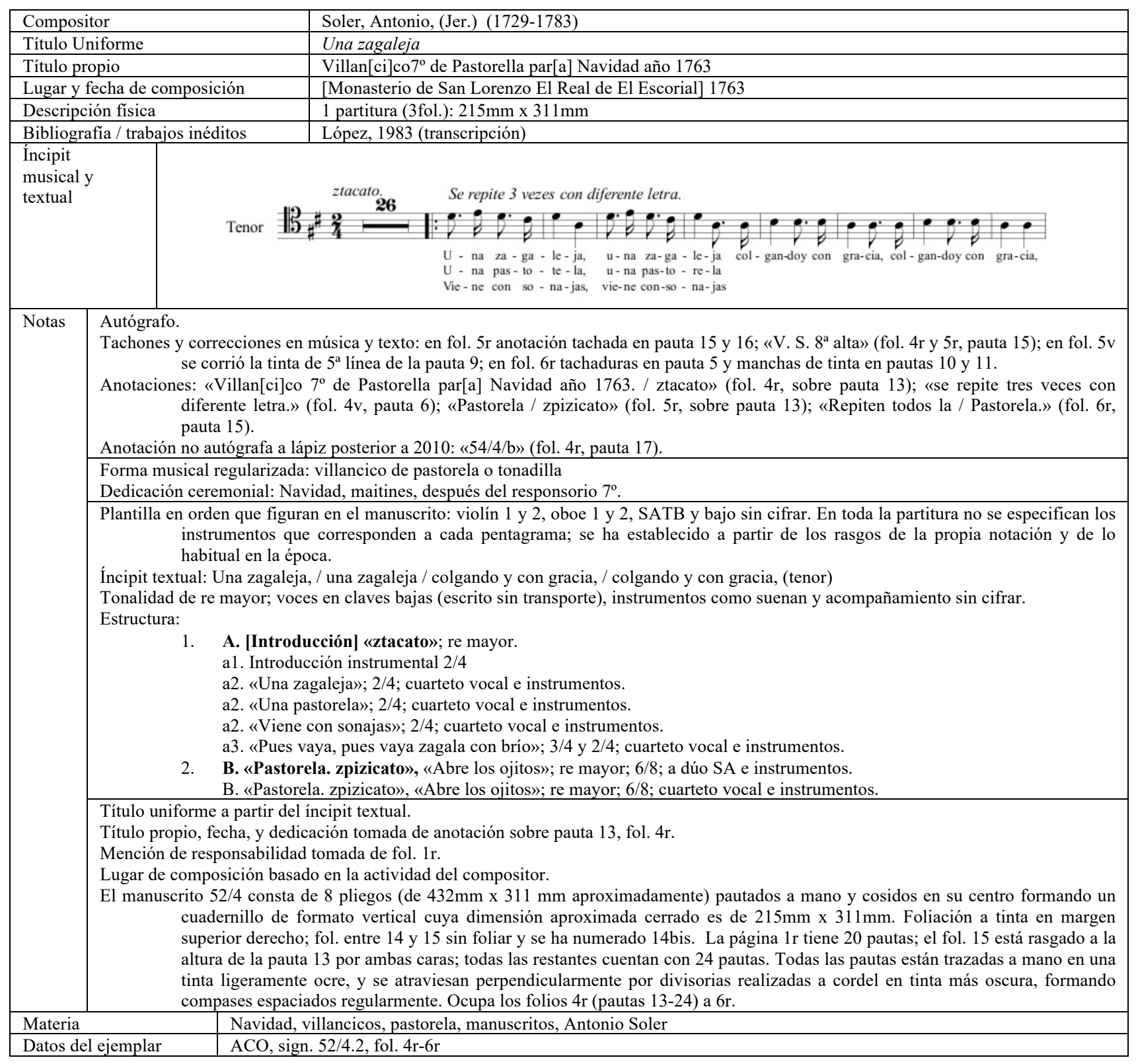




\section{CUADRO 3. FICHA DE CATALOGACIÓN DE ACO 52/4.3}

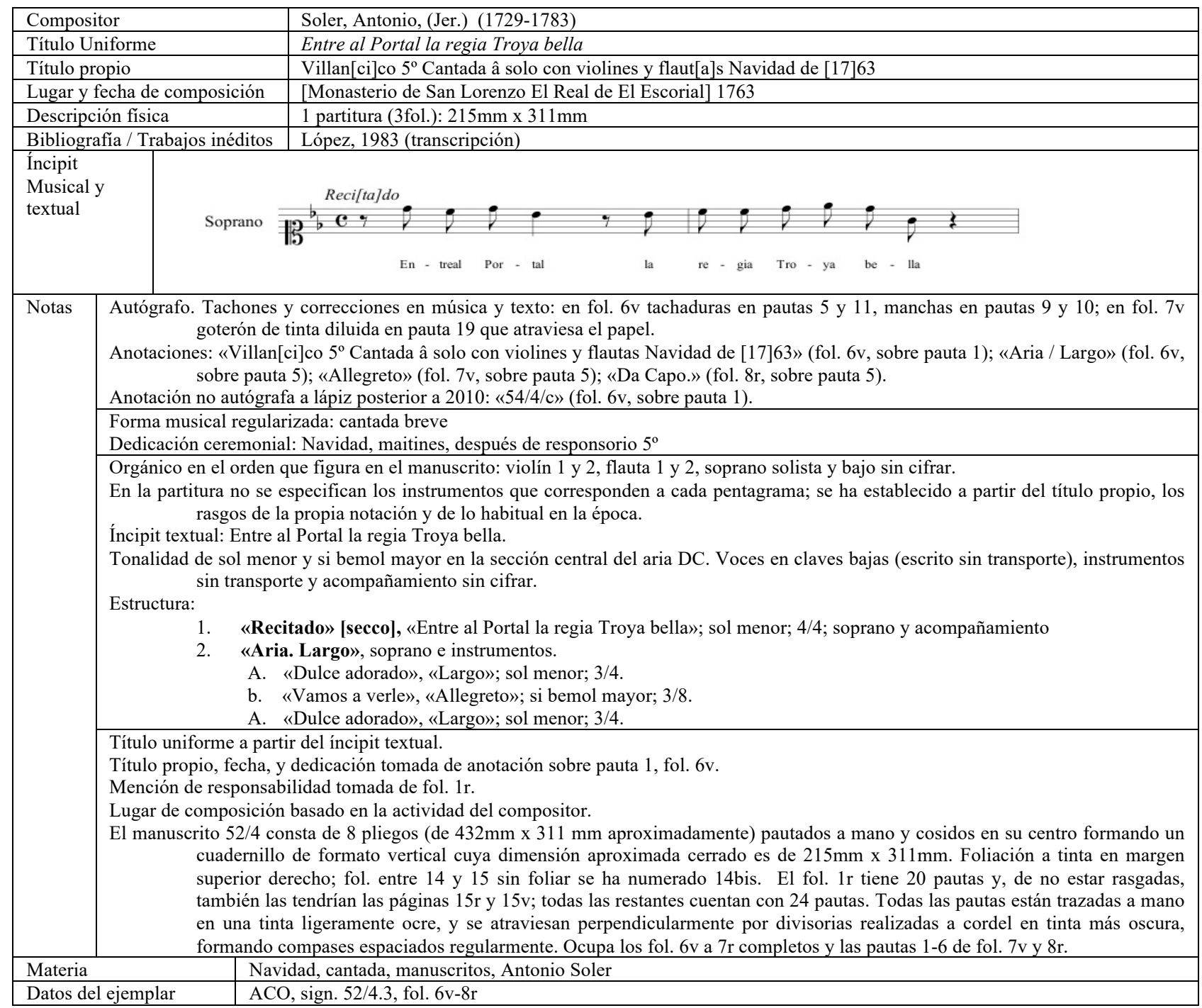


CUADRO 4. FICHA DE CATALOGACIÓN DE ACO 52/4.4

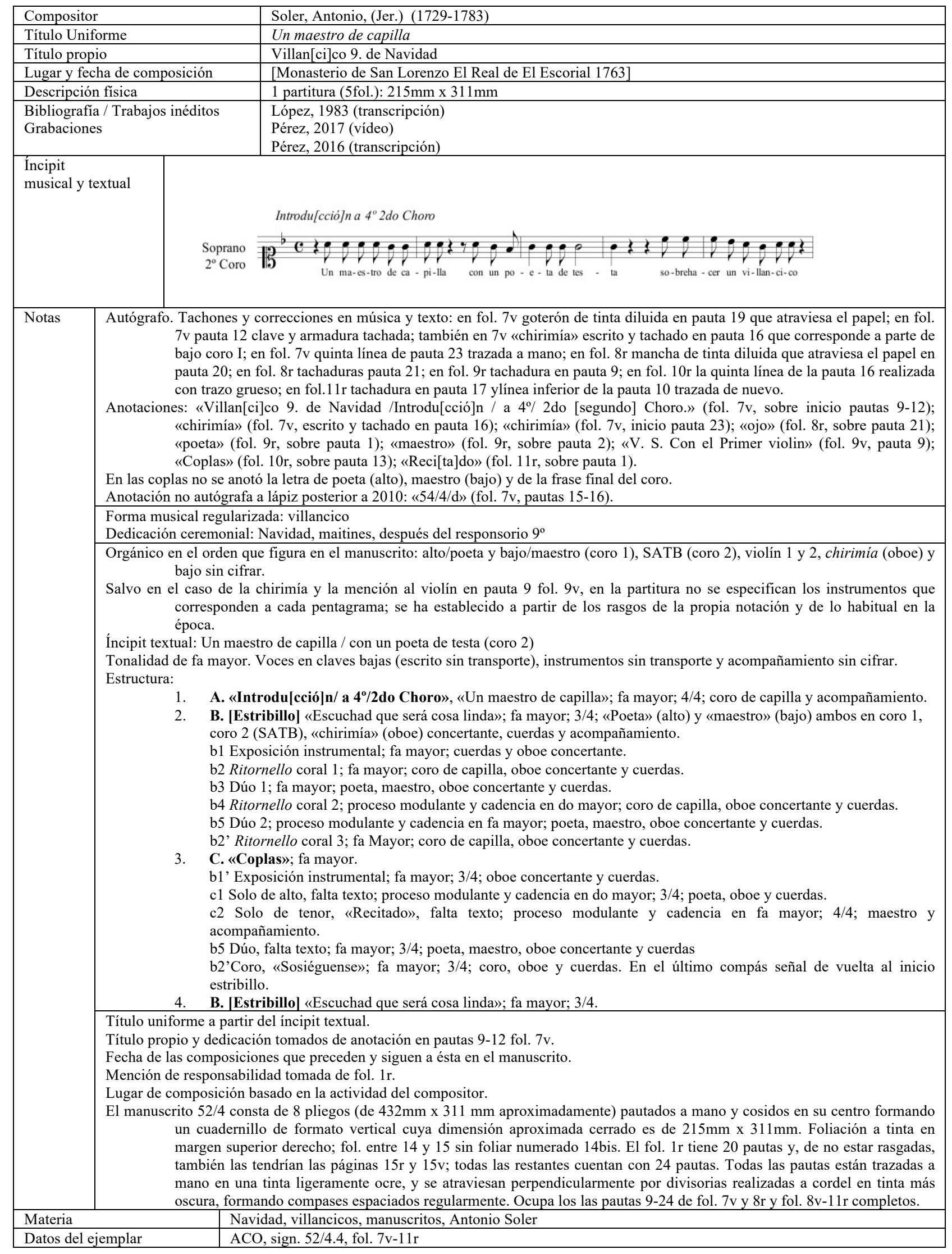




\section{CUADRO 5. FICHA DE CATALOGACIÓN DE ACO 52/4.5}

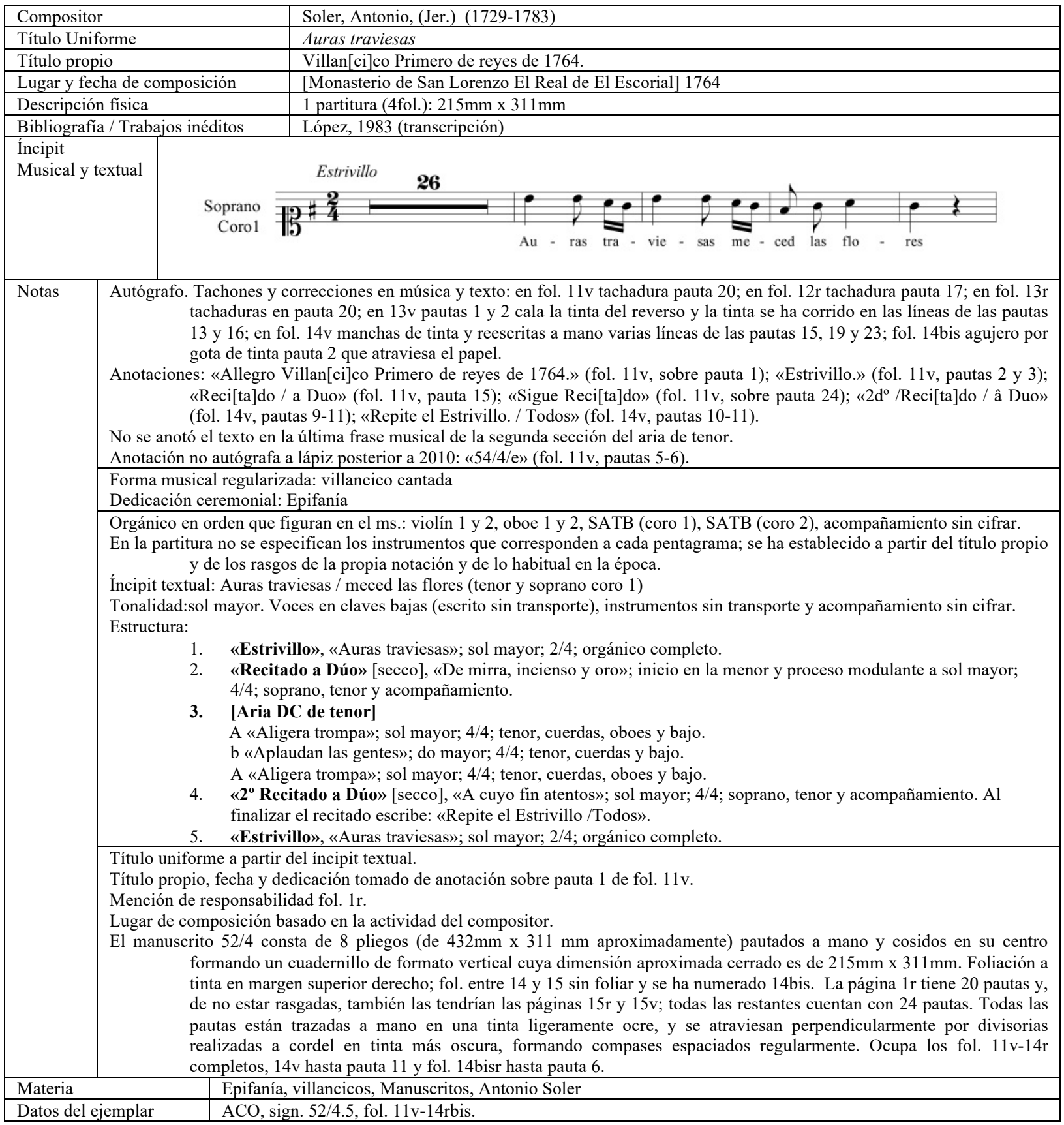


CUADRO 6. FICHA DE CATALOGACIÓN DE ACO 52/4.6

\begin{tabular}{|c|c|c|c|}
\hline \multicolumn{3}{|c|}{ Compositor } & Soler, Antonio, (Jer.) (1729-1783) \\
\hline \multicolumn{3}{|c|}{ Título Uniforme } & Ah che dissi infelice! \\
\hline \multicolumn{3}{|c|}{ Título propio } & Ultima scena, de la opera di la Didone. \\
\hline \multicolumn{3}{|c|}{ Lugar y fecha de composición } & [Monasterio de San Lorenzo El Real de El Escorial, 1764-1779] \\
\hline \multicolumn{3}{|c|}{ Descripción física } & 1 partitura (2fol.): $215 \mathrm{~mm} \times 311 \mathrm{~mm}$ \\
\hline \multicolumn{3}{|c|}{ Bibliografía / Trabajos } & Berná, 2020 (Transcripción y reconstrucción) \\
\hline \multicolumn{2}{|c|}{$\begin{array}{l}\text { Íncipit } \\
\text { musical y } \\
\text { textual }\end{array}$} & \multicolumn{2}{|c|}{ Soprano } \\
\hline \multirow[t]{4}{*}{ Notas } & \multicolumn{3}{|c|}{ 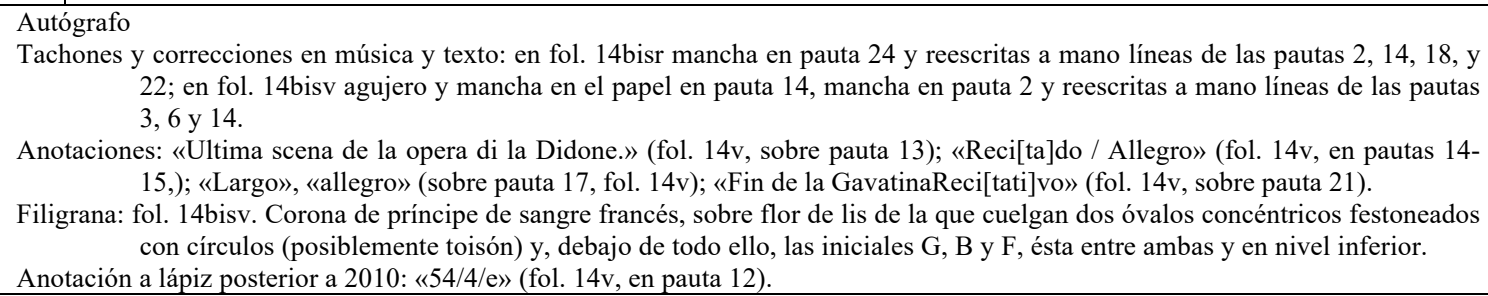 } \\
\hline & \multicolumn{3}{|c|}{ Forma musical regularizada: recitativo acompañado } \\
\hline & \multicolumn{3}{|c|}{ 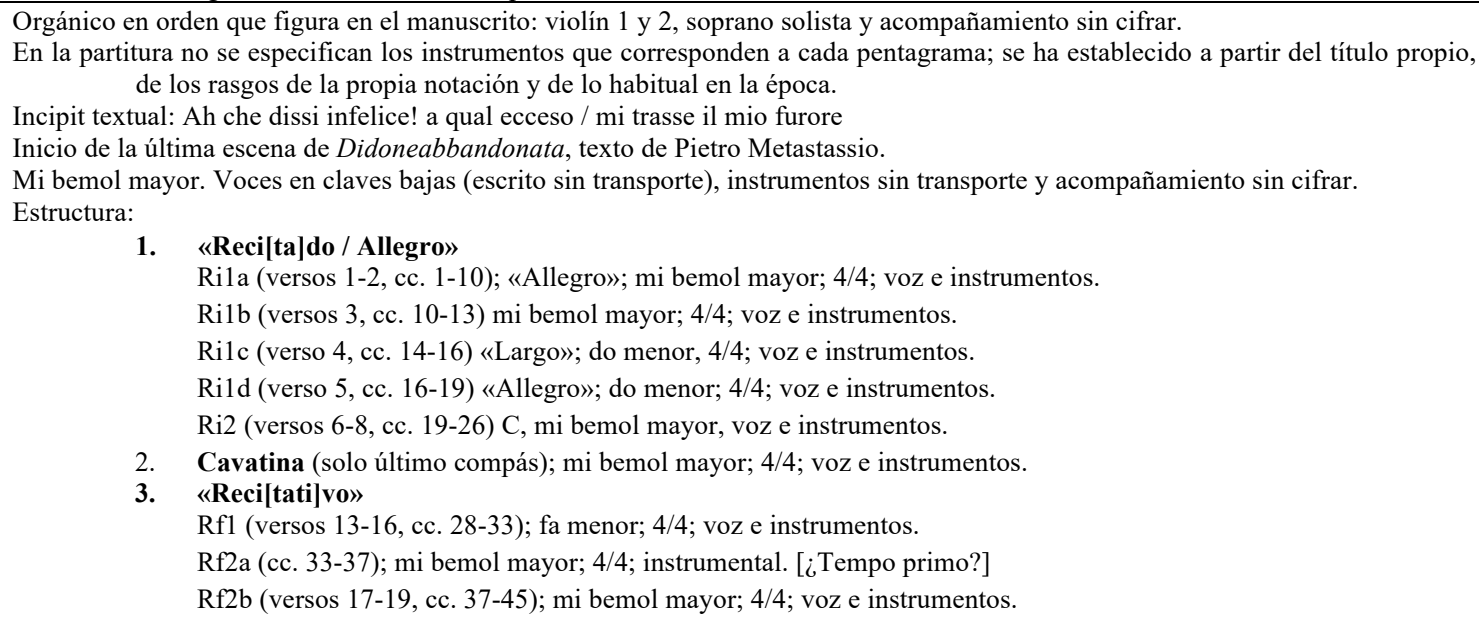 } \\
\hline & \multicolumn{3}{|c|}{$\begin{array}{l}\text { Título uniforme a partir del íncipit textual. } \\
\text { Título propio tomado de anotación sobre pauta } 13 \mathrm{de} \text { fol. } 14 \mathrm{v} \text {. } \\
\text { Fecha derivada del rango temporal delimitado por las composiciones que preceden y siguen a ésta en el manuscrito. } \\
\text { Mención de responsabilidad tomada de fol. } 1 \mathrm{r} \text {. } \\
\text { Lugar de composición basado en la actividad del compositor. } \\
\text { El manuscrito } 52 / 4 \text { consta de } 8 \text { pliegos (de } 432 \mathrm{~mm} \text { x } 311 \mathrm{~mm} \text { aproximadamente) pautados a mano y cosidos en su centro formando } \\
\text { un cuadernillo de formato vertical cuya dimensión aproximada cerrado es de } 215 \mathrm{~mm} \text { x } 311 \mathrm{~mm} \text {. Foliación a tinta en } \\
\text { margen superior derecho; fol. entre } 14 \text { y } 15 \text { sin foliar y se ha numerado } 14 \mathrm{bis} \text {. La página } 1 \mathrm{r} \text { tiene } 20 \text { pautas y, de no } \\
\text { estar rasgadas, también las tendrían las páginas } 15 \mathrm{r} \text { y } 15 \mathrm{v} \text {; todas las restantes cuentan con } 24 \text { pautas. Todas las pautas } \\
\text { están trazadas a mano en una tinta ligeramente ocre, y se atraviesan perpendicularmente por divisorias realizadas a } \\
\text { cordel en tinta más oscura, formando compases espaciados regularmente. Ocupa los folios } 14 \mathrm{v} \text { pautas } 13-24 \text {, fol. } 14 \mathrm{bisr} \\
\text { pautas } 13-24 \text { y fol. } 14 \text { bisv pautas } 1-4 \text {. }\end{array}$} \\
\hline \multicolumn{2}{|c|}{ Materia } & \multicolumn{2}{|c|}{ Ópera, manuscritos, Antonio Soler, Dido Abbandonata, Pietro Metastasio } \\
\hline \multicolumn{2}{|c|}{ Datos del ejemplar } & \multicolumn{2}{|c|}{ ACO, sign. 52/4.6, fol. 14v-14bisv. } \\
\hline
\end{tabular}




\section{CUADRO 7. FICHA DE CATALOGACIÓN DE ACO 52/4.7}

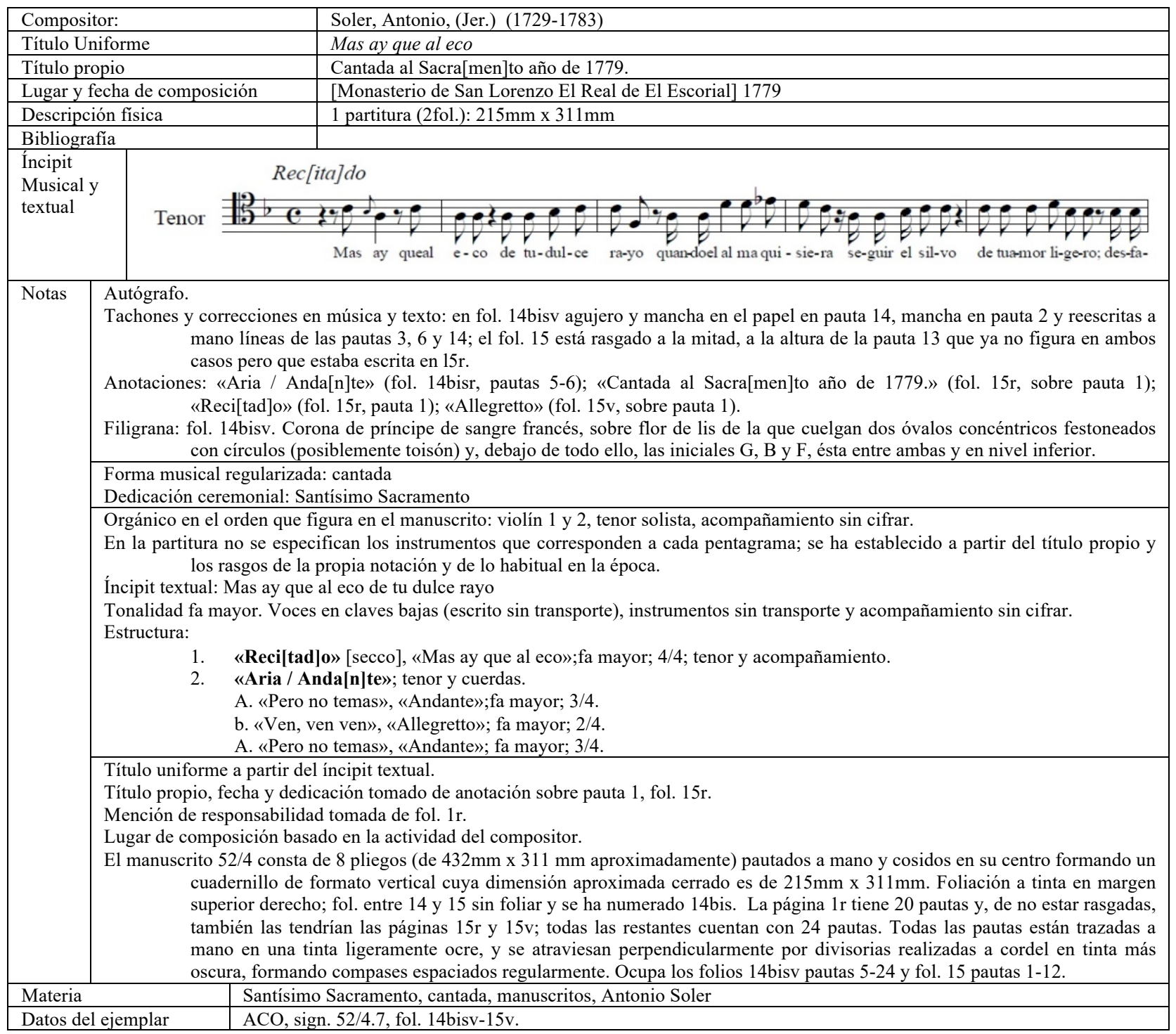




\section{CUADRO 8. TEXTOS DE ACO 52/4.6, MOJADOS 1752 Y FORNARI 1763}

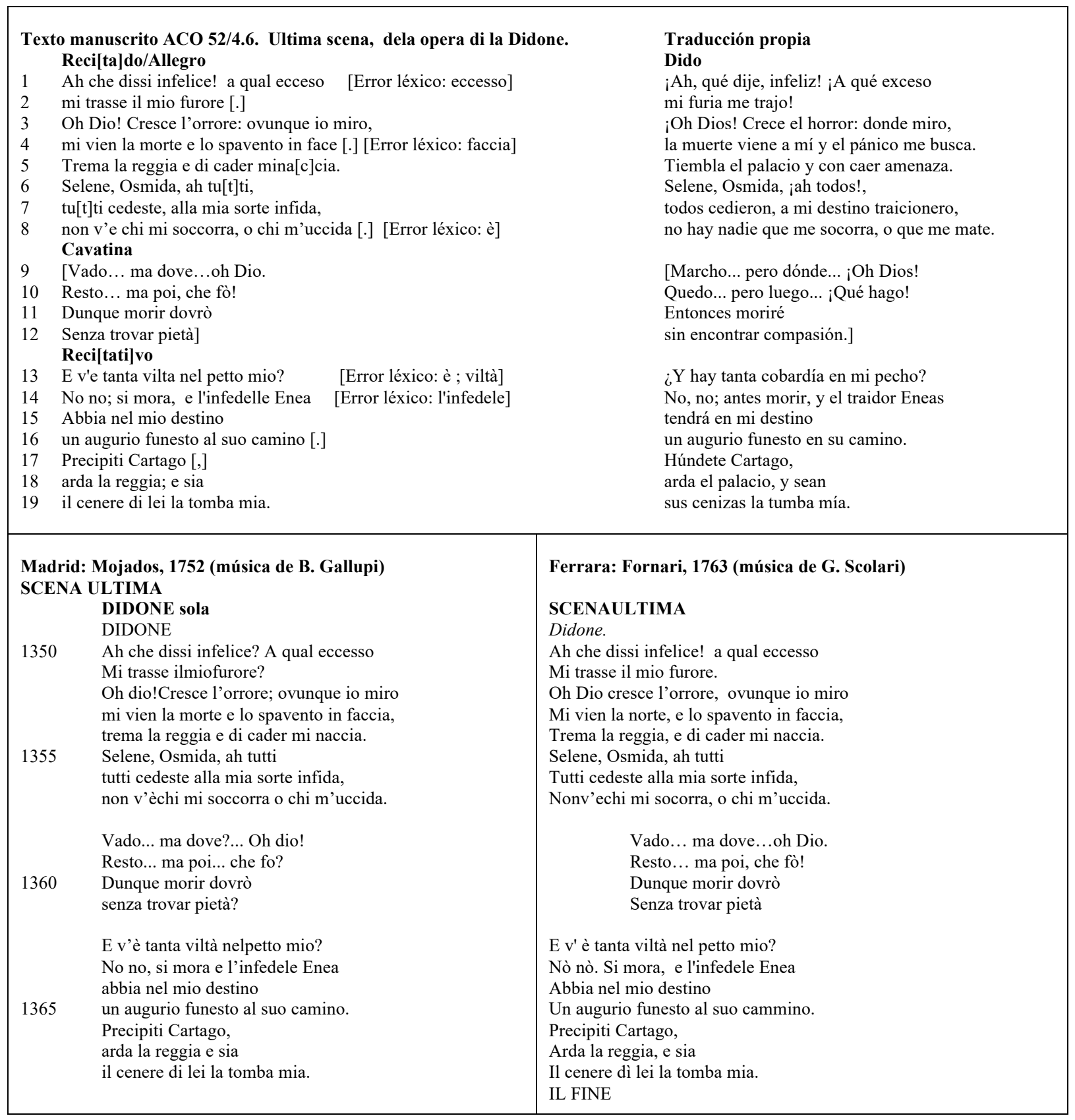


ANEXO I. Transcripción musical de ACO, SIGN. 52/4.6

\section{Ah che dissi infelice!}

Ulima scena de la opera di la Didone

Pietro Metastasio (libreto)

Antonio Soler (música) Juan Berná Pérez (transcripción)
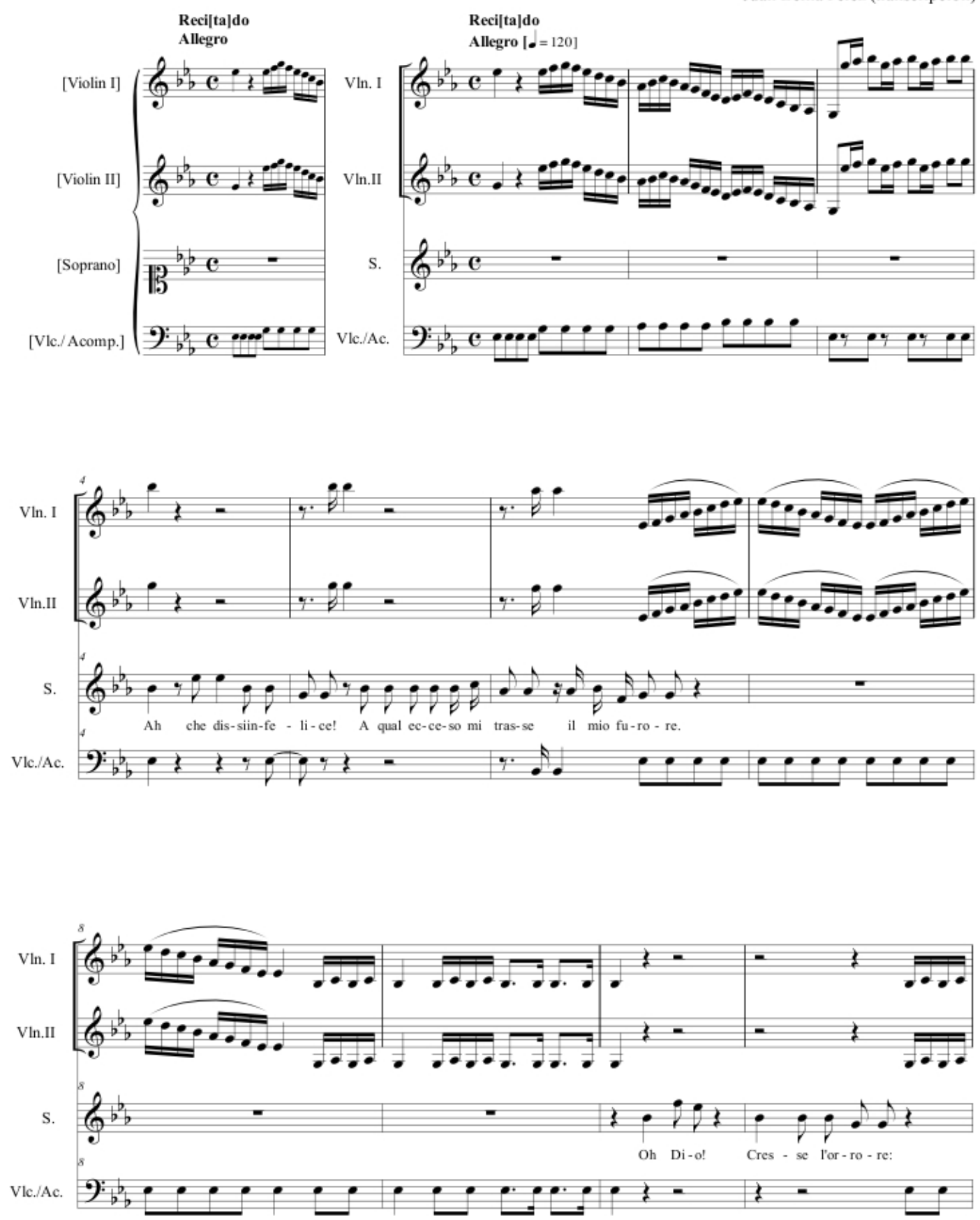
ACO 52/4.6 Berná (trans)
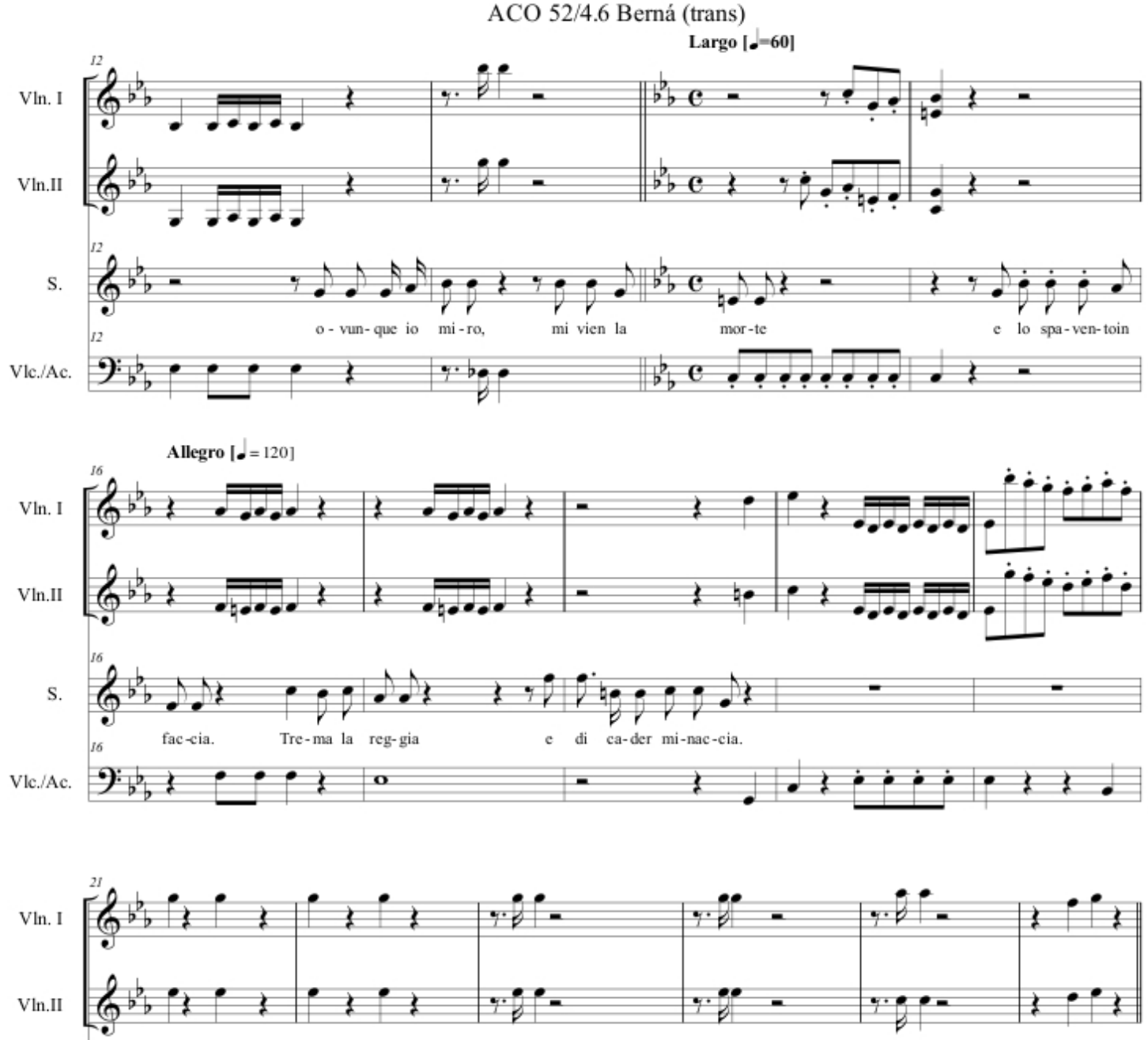

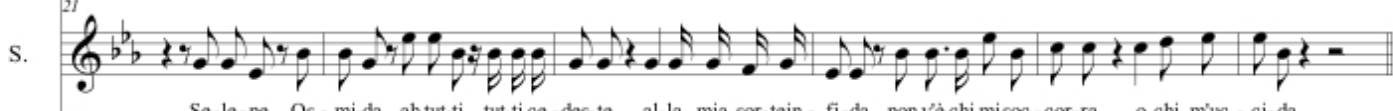

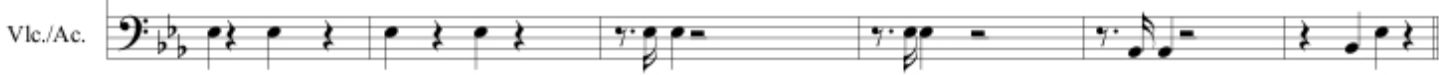

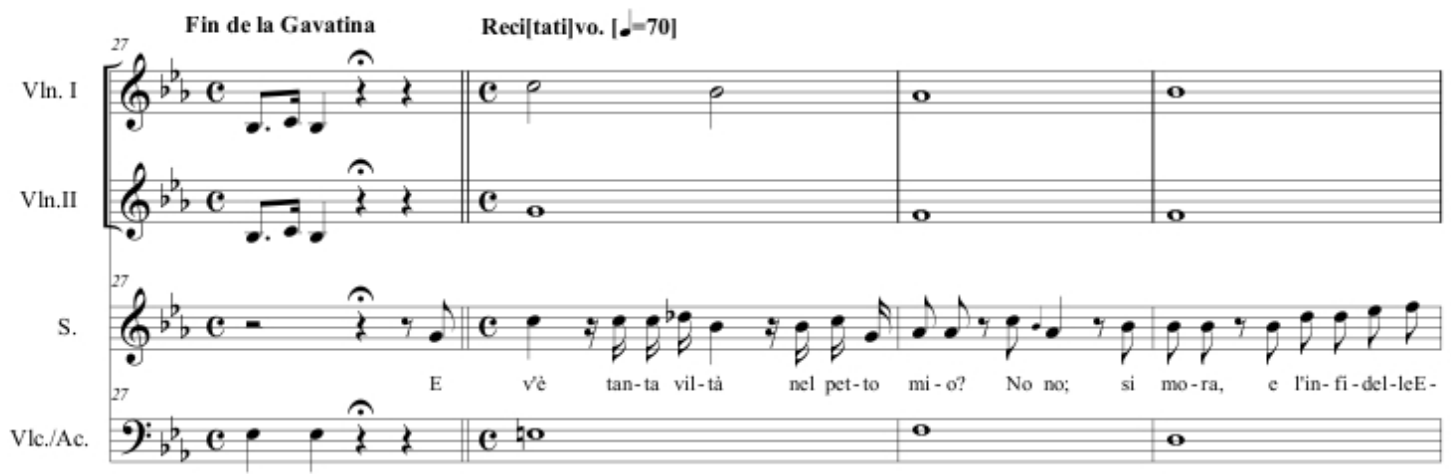


ACO 52/4.6 Berná (trans)
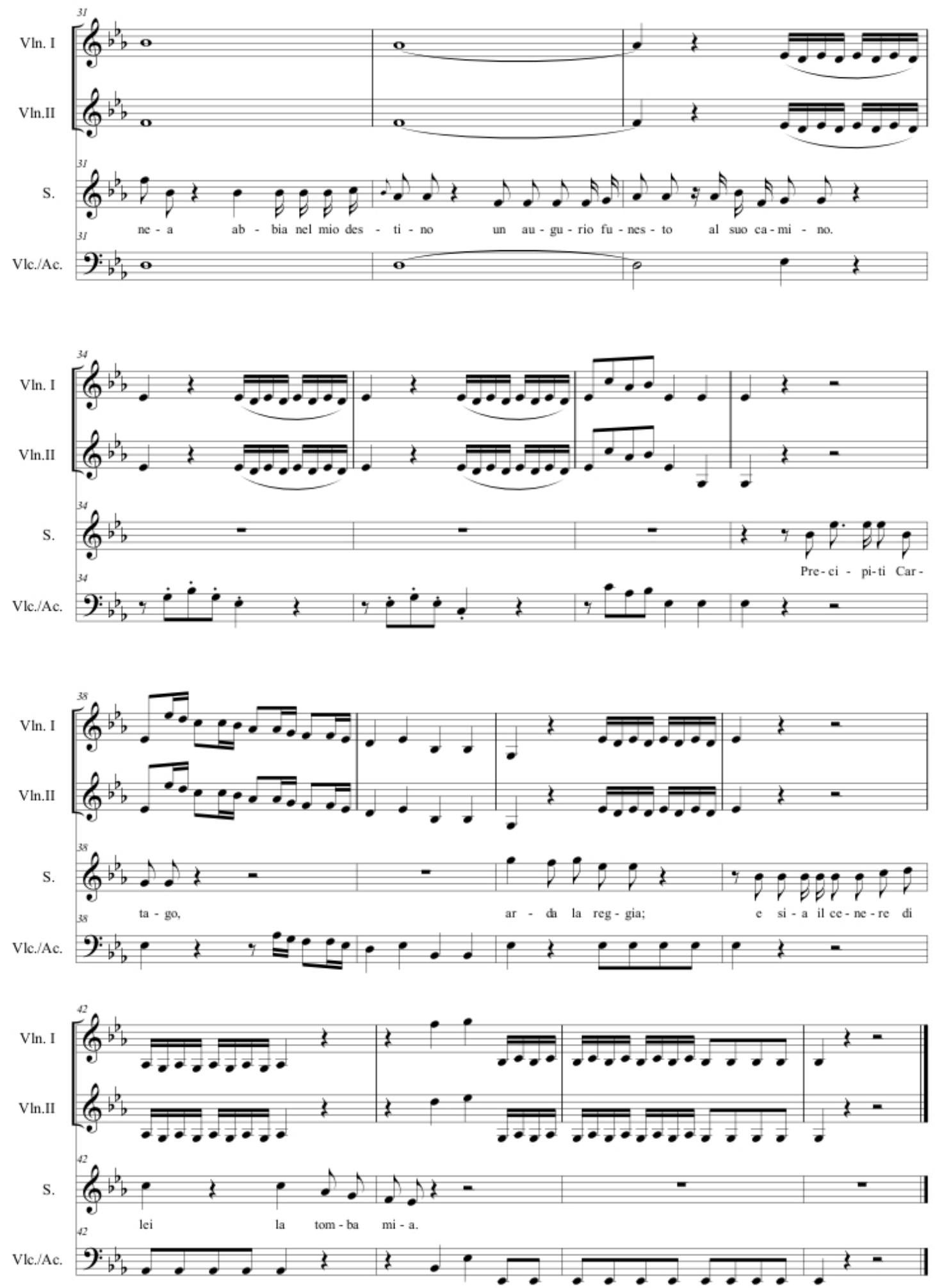